\title{
3D printed Poly( $\varepsilon$-caprolactone)/Hydroxyapatite scaffolds for Bone Tissue Engineering: A comparative study on composite preparation by melt blending or solvent casting techniques and influence of bioceramic content on scaffold properties
}

\author{
Sara Biscaia 1,+, Mariana V. Branquinho ${ }^{2,3,+}$, Rui D. Alvites 2,3,+, Rita Fonseca 1, Ana Catarina Sousa 2.3, Sílvia S. \\ Pedrosa 2,3,4, Ana R. Caseiro 2,3,5, Fernando Guedes ${ }^{2.3}$, Tatiana Patrício ${ }^{1}$, Tânia Viana ${ }^{1}$, Artur Mateus ${ }^{1}$, Ana C. \\ Maurício ${ }^{2.3, *}$ and Nuno Alves $1, *$
}

1 Centre for Rapid and Sustainable Product Development (CDRSP), Polytechnic Institute of Leiria, Portugal; sara.biscaia@ipleiria.pt (S.B.); ana.r.fonseca@ipleiria.pt (R.F.); tatiana.patricio@ipleiria.pt (T.P); taniaviana@gmail.com (T.V.); artur.mateus@ipleiria.pt (A.M.); nuno.alves@ipleiria.pt (N.A.)

2 Veterinary Clinics Department, Abel Salazar Biomedical Sciences Institute (ICBAS), University of Porto (UP), Rua de Jorge Viterbo Ferreira, n 228, 4050-313 Porto, Portugal; m.esteves.vieira@gmail.com (M.V.B.); ruialvites@hotmail.com (R.D.A.); anacatarinasoaressousa@hotmail.com (A.C.S.); s.santospedrosa@gmail.com (S.P.); fernando.t.guedes@gmail.com (F.G.); rita.caseiro.santos@gmail.com (A.R.C.)

3 Animal Science Studies Centre (CECA), Agroenvironment, Technologies and Sciences Institute (ICETA), University of Porto (UP), Rua D. Manuel II, Apartado 55142, 4051-401 Porto, Portugal;

4 Catholic University of Portugal, CBQF- Centre of Biotechnology and Fine Chemistry - Associated Laboratory, Faculty of Biotechnology, Rua de Diogo Botelho 1327, 4169-005 Porto, Portugal.

5 Vasco da Gama Research Center (CIVG)/ Vasco da Gama University School (EUVG), Av. José R. Sousa Fernandes 197, 3020-210, Lordemão, Coimbra, Portugal;

* Correspondence: acmauricio@icbas.up.pt

+ Both authors contributed equally.

$¥$ Both authors contributed equally as last authors.

\begin{abstract}
Bone tissue engineering has been developed in the past decades, with the engineering of bone substitutes on the vanguard of this regenerative approach. PCL based scaffolds are fairly applied for bone regeneration, and several composites have been incorporated, as to improve the devices' mechanical properties and tissue ingrowth. In this study, HA was incorporated on PCL based scaffolds with two different proportions, 80:20 and 60:40. Devices were produced with two different techniques, $\mathrm{SC}$ and $\mathrm{MB}$, and further investigated with regards to their mechanical characteristics and in vitro cytocompatibility. Results show the MB devices to present more promising mechanical properties, along with the incorporation of HA. The latter is also related to an increase in osteogenic activity and promotion. Overall, this study suggest PCL:HA scaffolds to be promising candidates for bone tissue engineering, particularly when produced by the $\mathrm{MB}$ method.
\end{abstract}

Keywords: Polycaprolactone; Hydroxyapatite; Composites; Solvent casting; Melt blending; 3D printing; Cytocompatibility; Bone tissue engineering

\section{Introduction}

Bone tissue engineering allows the development of alternative strategies to repair bone defects caused by disease or trauma that cannot be healed spontaneously in the living tissue. This approach emerged due to the limitations of the conventional therapies that usually includes transplantation, surgical reconstitution, and artificial prosthesis. Bone tissue engineering requires the incorporation of osteoblasts on $3 \mathrm{D}$ scaffolds for 
adhesion, proliferation and differentiation of cells, as well as nutrient and oxygen availability [1-3].

There are several requirements that should be considered to obtain an efficient 3D scaffold. In the initial stage, the biocompatibility and bioactivity of the support have a major impact on cell attachment, and an appropriate macro and micro porosity and shape allow the tissue in-growth and delivery of nutrients and oxygen to the cells. Furthermore, the scaffold should have sufficient mechanical strength to provide the structural requirements of the substituted tissue, and degradation rate must be gradual for cell growth and proliferation, to promote the creation of a new bone tissue $[2,4,5]$.

The fabrication of 3D scaffolds with high resolution and control on micro/nano level structure are facilitated using 3D printing technologies. Extrusion-based techniques consist in a computer-controlled layer-by-layer deposition where polymer filament fused is extruded through a nozzle. This technology has been used to process various biomaterials, mainly thermoplastics, being polycaprolactone (PCL), polylactic acid (PLA), and poly(lactic-co-glycolic) acid (PLGA) the most frequently used for bone tissue engineering applications. However, due to their low bioactivity, the development of composite scaffolds has been especially explored by combining polymers with calciumphosphate based materials [6]. The composites are comprised of two or more materials, aiming at the development of more efficient scaffolds, by combining regenerative properties of more than one biomaterial [7]. In addition, composites integrating calcium phosphates and polymers combine good mechanical properties with good biocompatibility, reaching to a 3D substitute that mimics the heterogeneity and hierarchical structure typical of the native extracellular bone matrix $[8,9]$. Therefor, the use of hydroxyapatite (HA) can be justified because of its chemical similarity to the natural mineral component of bone tissue. Additionally, HA has the ability to integrate into bone structures and support its growth without breaking or dissolving the tissue (bioactive properties) $[10,11]$. HA has been previously blended with PCL, a polymer considered safe by Food and Drug Administration (FDA) [12]. PCL, through its melt processing, allows to obtain 3D porous scaffolds with highly interconnected porous network $[5,12]$.

With respect to the production of the composite structures, their properties are mainly dependent on the nature of the materials and preparation method. In the present study, one of the objectives considered was to investigate how the solvent can influence the resultant composite mixture and its properties. Concerning this topic, a few relevant studies regarding solvents' impact in the solvent casting technique have been reported. Patlolla et al [13] conducted a study where $20 \% \mathrm{HA} / 80 \% \beta$-TCP and PCL composites were produced using either methylene chloride (MC) or a combination of MC and dimethylformamide (MC+DMF) solvents. This study demonstrate that the produced structures presented uniform fibers and homogeneous ceramic dispersions, and the solvent or solvent combination used to produce the composites proved to be a determining factor to define its properties, thus affecting cell growth kinetics. In another study, Choudhury and colleagues [14], investigated the effect of different solvents 1,1,1,3,3,3-hexafluoro-2-propanol (HFIP), dichloromethane (DCM) and chloroform (CF), to fabricate PLA scaffolds. PLA/DCM scaffolds presented more thermal stability and a stiffer base compared with PLA/HFIP and PLA/CF scaffolds. However, the PLA/CF scaffold showed higher porosity as against PLA/HFIP scaffold, which benefits the requirements for bone tissue engineering.

Altogether, it has been established that different solvents will interact with the polymer quite differently. This findings appeared to be caused by I) proton conductivity [15-17], II) solvent volatility [14, 15], which has been found to be better with a less volatile solvent, combined with III) stronger solvent-polymer interactions [15]; to address the uniformity requirements of the scaffold/structure and the regularity of polymer surface. Additionally, the choice of solvent can impact the dispersion of particles within a polymeric matrix, and all these features can affect composite structure, morphology and properties, which may, in turn, affect cell behaviour and tissue ingrowth and regeneration [13]. 
In this work, in addition to the incorporation of a ceramic amount of 20 and $40 \mathrm{wt} \%$ on PCL, we analysed the influence of the two mixture techniques (solvent casting (SC) and melt blending (MB)) on the properties of PCL and PCL/HA composites. Following, the six different groups considered (PCL SC, PCL MB, PCL/HA 80:20 SC, PCL/HA 80:20 MB, PCL/HA 60:40 SC and PCL/HA 60:40 MB) were 3D printed through an extrusion-based technique and their physicochemical properties were further analysed. Following, in vitro assays were taken, applying mesenchymal stem cells, as to evaluate the regenerative potential of the produced scaffolds.

\section{Results}

\subsection{Fabrication and characterization of $3 D$ scaffolds}

The PCL and PCL/HA composites were used for the fabrication of 3D printed scaffolds. The chemical structure of the PCL and PCL/HA scaffolds was analysed using FTIR-ATR spectroscopy (Error! Reference source not found. A). The spectra of all fabricated scaffolds present structural bands of PCL and HA that only differ in terms of intensity. The characteristic peaks of PCL appear at 2865 and $2941 \mathrm{~cm}^{-1}$ that correspond to the symmetric and asymmetric stretching of the $\mathrm{CH}_{2}$ group, and $1720 \mathrm{~cm}^{-1}$ related to carbonyl stretching $(\mathrm{C}=\mathrm{O})$. Furthermore, the band at $1239 \mathrm{~cm}^{-1}$ correspond to the $\mathrm{C}-\mathrm{O}$ and C-C stretching characteristic of the crystalline phase and at $1164 \mathrm{~cm}^{-1}$ is related to the symmetric COC stretching. Regarding HA, the typical bands are present at 1088, 600 and $568 \mathrm{~cm}^{-1}$ which are attributed to $v_{3}$ and $v_{4}$ of P-O stretching.

Error! Reference source not found. B presents the element analysis of the PCL/HA scaffolds which also confirms the incorporation of HA in the composites, with the presence of phosphorous and calcium elements.

A
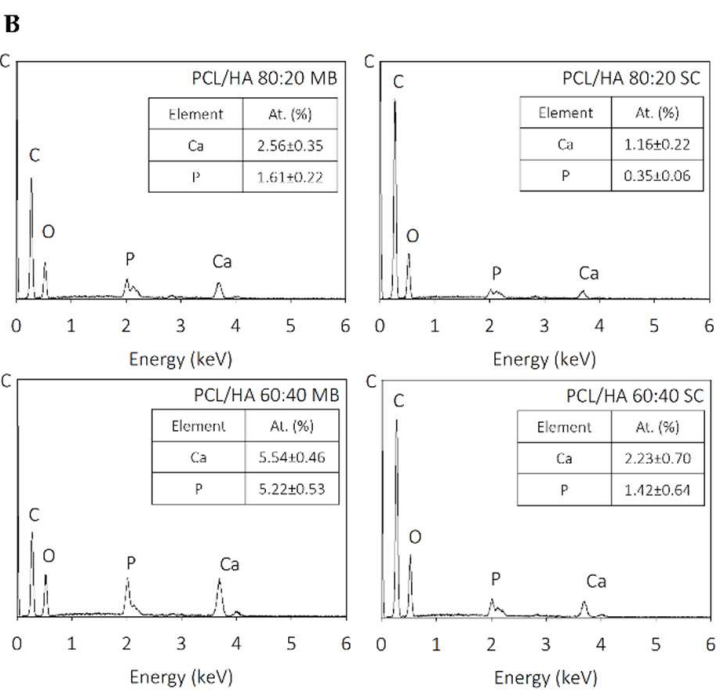

Figure 1. FTIR spectra of pure HA and PCL/HA composites (A); and EDX spectra and quantitative results showing elemental composition of PCL/HA composites with predominant calcium and phosphorous atoms (B).

Thermal properties of PCL and PCL/HA scaffolds were assessed by DSC thermograms, shown in Error! Reference source not found. and the main data is reported in Error! Reference source not found.. The crystallization temperatures present a small decreased in PCL/HA 60:40 composites and the incorporation of the ceramic kept the melting temperature of neat PCL. Furthermore, the endothermic melting enthalpies decreased with the addition of HA. The degrees of crystallinity in SC samples, however, are similar with an evident increase in $\mathrm{MB}$ composites. 
A

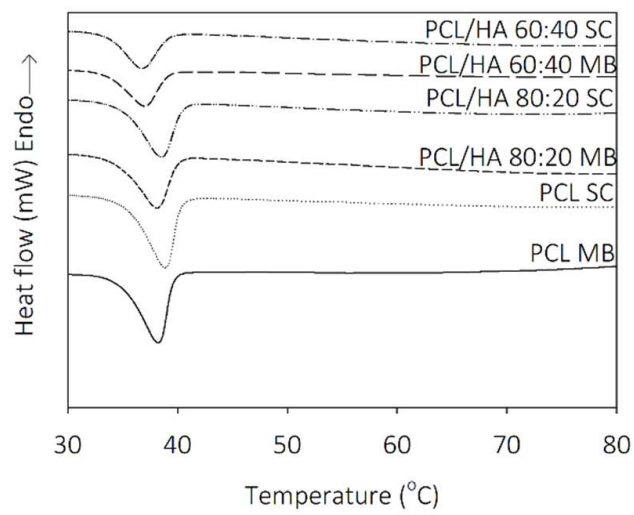

B

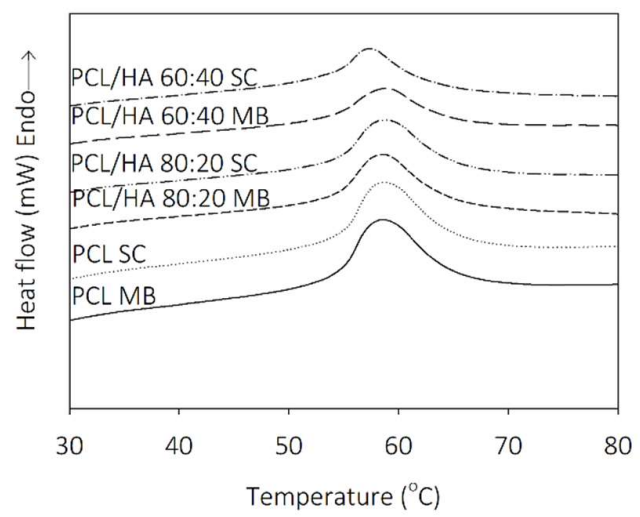

C

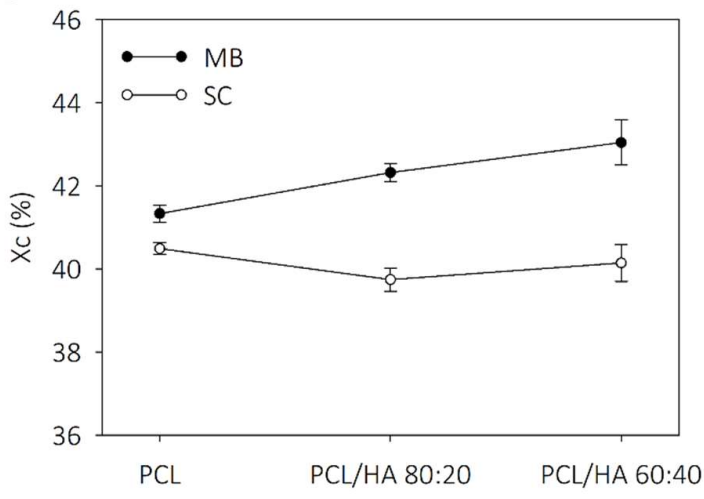

Figure 2. DSC thermograms: (A) cooling runs and (B) second heating runs; and (C) degree of crystallinity of PCL and PCL/HA composites.

Table 1. Thermal properties of PCL and PCL/HA composites by DSC, TGA and DTG.

\begin{tabular}{|c|c|c|c|c|c|c|c|}
\hline \multirow[t]{2}{*}{$\begin{array}{l}\text { HA Content } \\
(w t \%)\end{array}$} & \multirow[t]{2}{*}{ Method } & \multicolumn{4}{|c|}{ DSC } & \multirow{2}{*}{$\begin{array}{c}\text { TGA } \\
\text { M loss (\%) }\end{array}$} & \multirow{2}{*}{$\begin{array}{c}\text { DTG } \\
\operatorname{Td}\left({ }^{\circ} \mathrm{C}\right)\end{array}$} \\
\hline & & Tc $\left({ }^{\circ} \mathrm{C}\right)$ & $\operatorname{Tm}\left({ }^{\circ} \mathrm{C}\right)$ & $\Delta \mathrm{Hm}(\mathrm{J} / \mathrm{g})$ & Xc (\%) & & \\
\hline \multirow{2}{*}{0} & MB & $38.93 \pm 0.07$ & $58.43 \pm 0.18$ & $56.65 \pm 0.29$ & $41.33 \pm 0.21$ & $99.46 \pm 0.40$ & $386.52 \pm 1.85$ \\
\hline & SC & $38.13 \pm 0.11$ & $58.31 \pm 0.12$ & $56.48 \pm 0.20$ & $40.49 \pm 0.15$ & $99.30 \pm 0.58$ & $387.55 \pm 0.71$ \\
\hline \multirow{2}{*}{20} & MB & $38.68 \pm 0.15$ & $58.83 \pm 0.13$ & $47.24 \pm 0.34$ & $42.31 \pm 0.22$ & $80.43 \pm 0.60$ & $379.37 \pm 0.90$ \\
\hline & SC & $38.26 \pm 0.16$ & $58.93 \pm 0.54$ & $44.35 \pm 0.31$ & $39.74 \pm 0.28$ & $79.65 \pm 0.19$ & $378.93 \pm 1.45$ \\
\hline \multirow{2}{*}{40} & MB & $36.63 \pm 0.27$ & $57.65 \pm 0.60$ & $36.02 \pm 0.45$ & $43.04 \pm 0.54$ & $63.46 \pm 3.10$ & $369.19 \pm 1.03$ \\
\hline & SC & $37.08 \pm 0.07$ & $58.74 \pm 0.29$ & $33.60 \pm 0.37$ & $40.14 \pm 0.44$ & $60.10 \pm 0.33$ & $370.95 \pm 0.67$ \\
\hline
\end{tabular}

The thermal stability of the PCL and PCL/HA composites and the evidence of the amount of the HA in the composites were analysed by TGA thermograms and is presented in Error! Reference source not found.. Thermograms reveal a significant one step weight loss with degradation temperatures between 369 and $387^{\circ} \mathrm{C}$ (Table 2), that corresponds to the decomposition of PCL. Above $450{ }^{\circ} \mathrm{C}$, no weight loss was observed. The results present a slight decrease in the degradation temperature with the addition of the bioceramic, as well as a decrease in mass loss, as a function of the amount of HA present in the sample. 
A

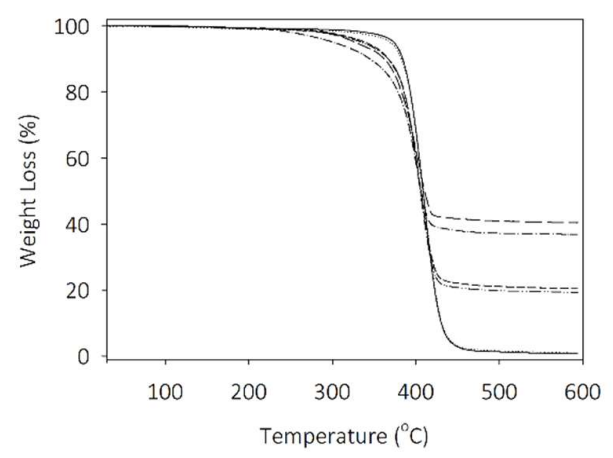

B

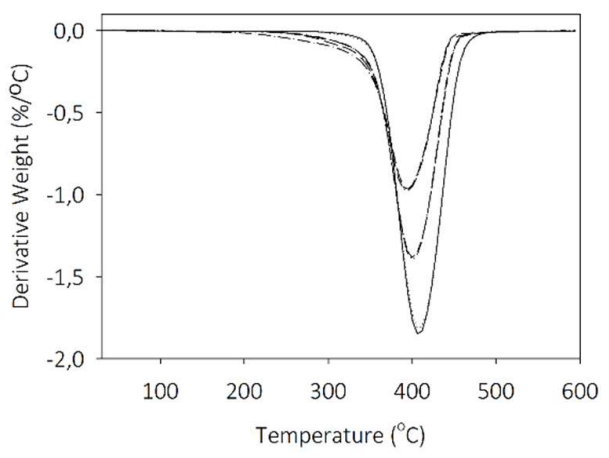

- PCLSC -- PCL/HA 80:20 SC -- PCL/HA 60:40 SC

PCLMB -. PCL/HA 80:20 MB -. PCL/HA 60:40 MB

Figure 3. (A) TGA and (B) DTG results of neat PCL and PCL/HA composites.

Figure 4A shows an example of a successfully fabricated scaffold with an interconnected porous structure. Further, the filament orientation, pores interconnectivity and porosity of all scaffolds were evaluated by Micro-CT (Figure 4B-D). Results suggest that the fabricated scaffolds present homogeneous 3D structure, like the 3D designed scaffold. Most of the scaffolds have a similar porosity ranging from 58-60\%, with the PCL MB scaffold standing out with $64 \%$.

A
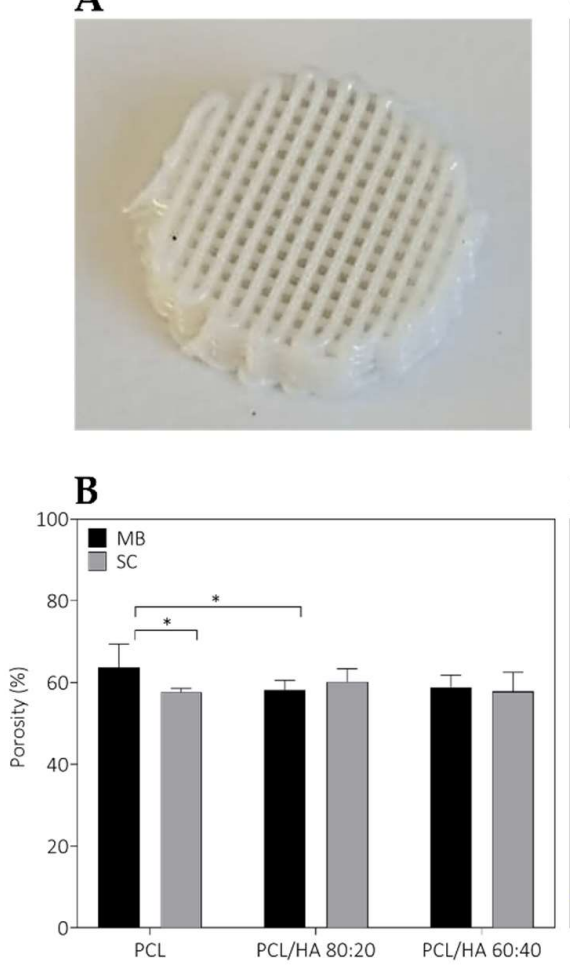

C

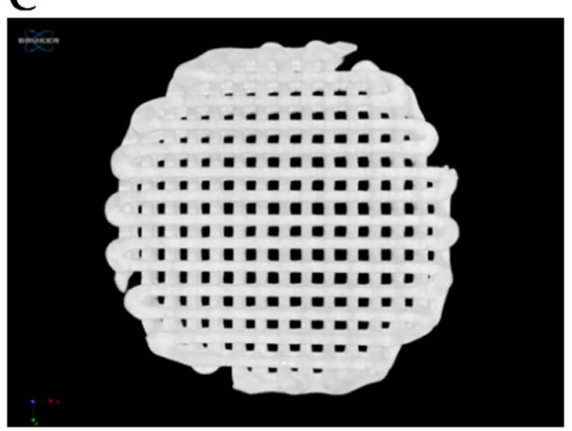

D

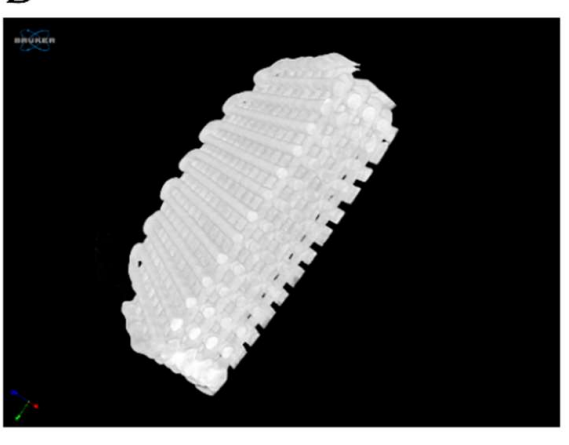

Figure 4. Final appearance of a PCL/HA scaffold (A), porosity obtained of the MB and SC scaffolds (B), Micro-CT image of a scaffold allowing the identification of interconnectivity between pores: topview $(C)$ and cross section view (D). Results presented in Mean \pm SE. Differences were considered statistically significant at $\mathrm{P} \leq 0.05$. Results significance are presented through the symbol $\left(^{*}\right)$, according to the $\mathrm{P}$ value, with one symbol corresponding to $0.01<\mathrm{P} \leq 0.05$. 
SEM micrographs of PCL, PCL/HA 80:20 and PCL/HA 60:40 scaffolds of the two blend methods (SC and MB) are shown in Figure 5Error! Reference source not found.A. As for the qualitative analysis of the images, MB and SC PCL scaffolds show filament surface with a small corrugation that became less visible in the PCL/HA groups. On the other hand, PCL/HA scaffolds present a rougher surface, when compared to the PCL groups. SEM analysis confirmed a homogeneous distribution of the HA on the polymer matrix, with some particles exposed on the filament surface. This aspect is more visible with higher amounts of HA (PCL/HA 60:40), where some particles agglomerations are also observed. Additionally, SC scaffolds still show micropores maintaining this appearance with a substantial number of pores but with larger size in the PCL/HA (60/40 $w t \%)$ formulation. As for the semi-quantitative analysis of the SEM images presented in Figure 5, the 3D printed structures present interconnected pores and uniform pore sizes. The filament and pore size were measured to analyse the structural characteristics of the proposed scaffolds and results are consistent with those of the design parameters. Between the groups produced by the SC method, the PCL/HA 60:40 and 80:20 groups presented pores with larger sizes, compared to the PCL group. For the six groups, the filament diameters of the scaffolds are mainly in the range of 300-306 $\mu \mathrm{m}$ for a nozzle with an inner diameter of $300 \mu \mathrm{m}$, and the pore size in the range of 300-318 $\mu \mathrm{m}$, smaller than the $350 \mu \mathrm{m}$ established in the scaffold design parameters.
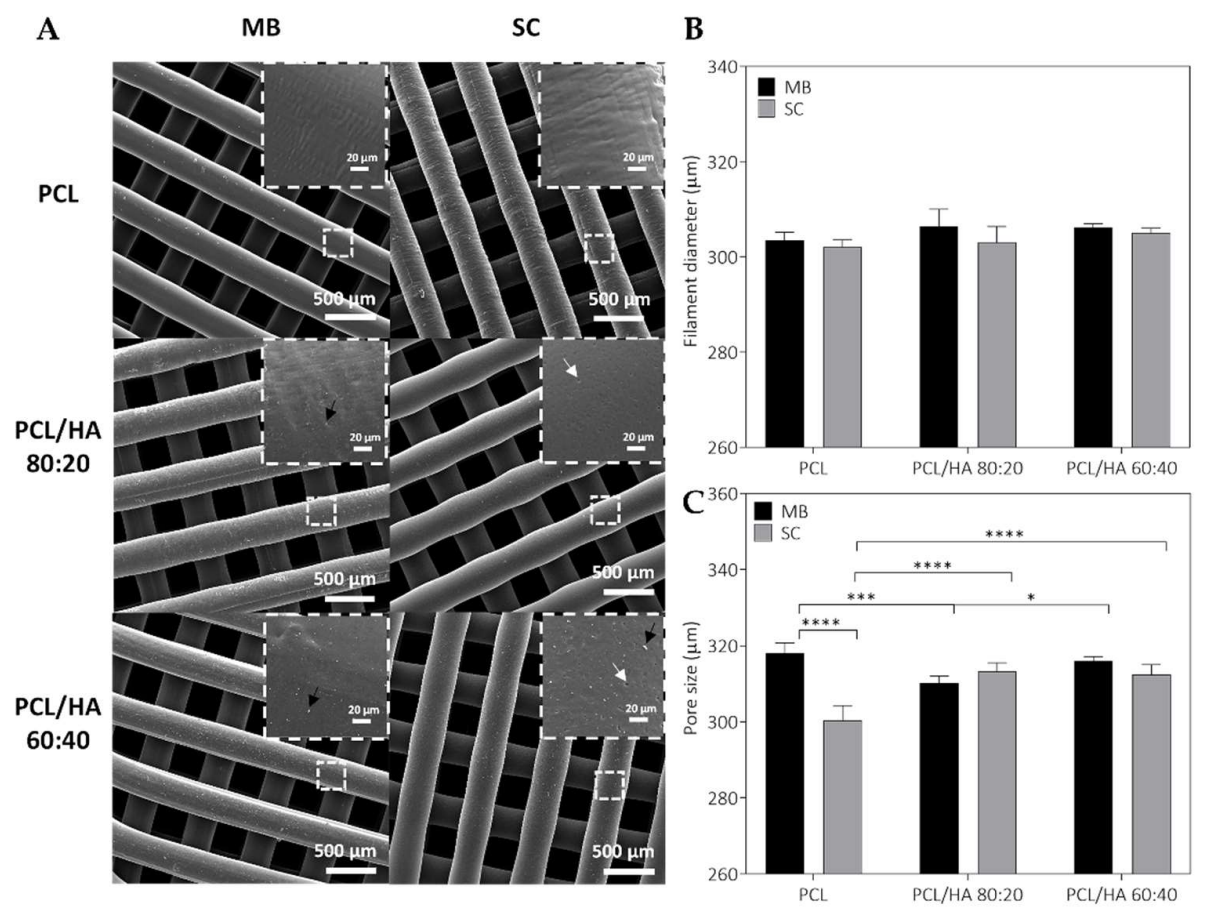

Figure 5. SEM micrographs of PCL and PCL/HA scaffolds, top-view and zoom-in view of the filament ("Black arrow" HA nanoparticles agglomeration and "White arrow" filament micropores (A), the corresponding filament diameter (B) and pore size (C). Results presented in Mean \pm SE. Differences were considered statistically significant at $\mathrm{P} \leq 0.05$. Results significance are presented through the symbol $\left({ }^{*}\right)$, according to the $\mathrm{P}$ value, with one, three or four symbols, corresponding to $0.01<\mathrm{P} \leq 0.05 ; 0.0001<\mathrm{P} \leq 0.001$ and $\mathrm{P} \leq 0.0001$, respectively.

The compressive modulus for the different scaffolds is presented in Error! Reference source not found. and all results from mechanical analysis are listed in the Error! Reference source not found.2. The incorporation of HA in the PCL polymer matrix contributes to the increase of the mechanical properties. However, they do not increase proportionally to the enhance of the ceramic concentration in the composite. In fact, differences between 
PCL/HA 80:20 and 60:40 are not statistically significant. Furthermore, the MB method presented for all groups better outcomes regarding mechanical properties, when compared to the SC groups. Finally, the MB method combined with the addition of HA provides the best mechanical response of the scaffolds (compressive modulus and maximum stress).

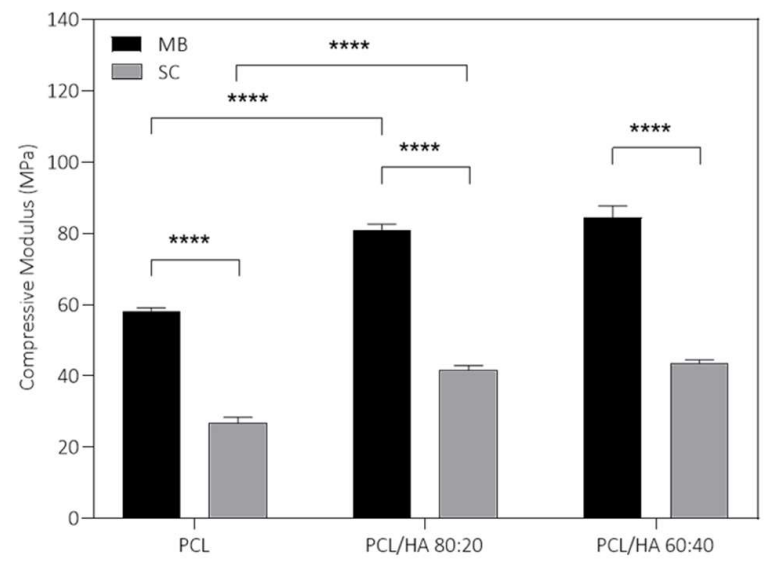

Figure 6. Compressive modulus obtained for the produced scaffolds by MB and SC. Results presented in Mean \pm SE. Differences were considered statistically significant at $\mathrm{P} \leq 0.05$. Results significance are presented through the symbol $\left(^{*}\right)$, according to the P value, with four symbols, corresponding to $\mathrm{P} \leq 0.0001$.

Table 2. Mechanical properties of compressive strength of scaffolds.

\begin{tabular}{cccc}
\hline $\begin{array}{c}\text { HA Content } \\
\text { (wt\%) }\end{array}$ & Method & $\begin{array}{c}\text { Compressive Modulus } \\
\mathbf{( M P a )}\end{array}$ & $\begin{array}{c}\boldsymbol{\sigma} \max (\mathbf{5 0} \% \text { strain) } \\
\mathbf{( M P a )}\end{array}$ \\
\hline \multirow{2}{*}{0} & MB & $58.30 \pm 0.78$ & $15.09 \pm 2.78$ \\
& SC & $26.76 \pm 1.70$ & $8.38 \pm 0.45$ \\
20 & MB & $81.01 \pm 1.59$ & $20.05 \pm 2.04$ \\
& SC & $41.59 \pm 1.31$ & $12.18 \pm 0.76$ \\
40 & MB & $84.84 \pm 3.26$ & $17.59 \pm 2.05$ \\
& SC & $43.43 \pm 1.09$ & $13.93 \pm 2.44$ \\
\hline
\end{tabular}

\subsection{Cytocompatibility assays}

\subsubsection{Cell viability assay}

A preliminary Presto Blue ${ }^{\mathrm{TM}}$ viability assay was conducted with Human Dental Pulp stem/stromal cells (hDPSCs) on the PCL MB and SC devices, to assess cellular viability and thus, the scaffolds' cytocompatibility. A control group with cells seeded directly on the well, without scaffold, was considered. Figure 7 and Table 3 present the results obtained. The hDPSCs cell population was selected for this assay, as they have shown promising results towards osteogenic differentiation and potential for bone regeneration in previous works [18-20] being an appropriate choice for this work purpose. Results suggest both PCL scaffolds to induce comparable cell viability outcomes, although, with the $\mathrm{MB}$ group presenting slightly better results overall the entire duration of the assay. Population's health and normal behaviour in culture was also confirmed by the control group. Considering the results obtained on the preliminary cytocompatibility assessment, both the PCL MB and the PCL SC group could be considered as control groups for further studies. However, the PCL MB group presented slightly better outcomes, in agreement with the biomaterials characterization results of both devices. From this point forward, PCL MB scaffold was used as a scaffold control group for further in vitro studies where different PCL/HA formulations were evaluated. 


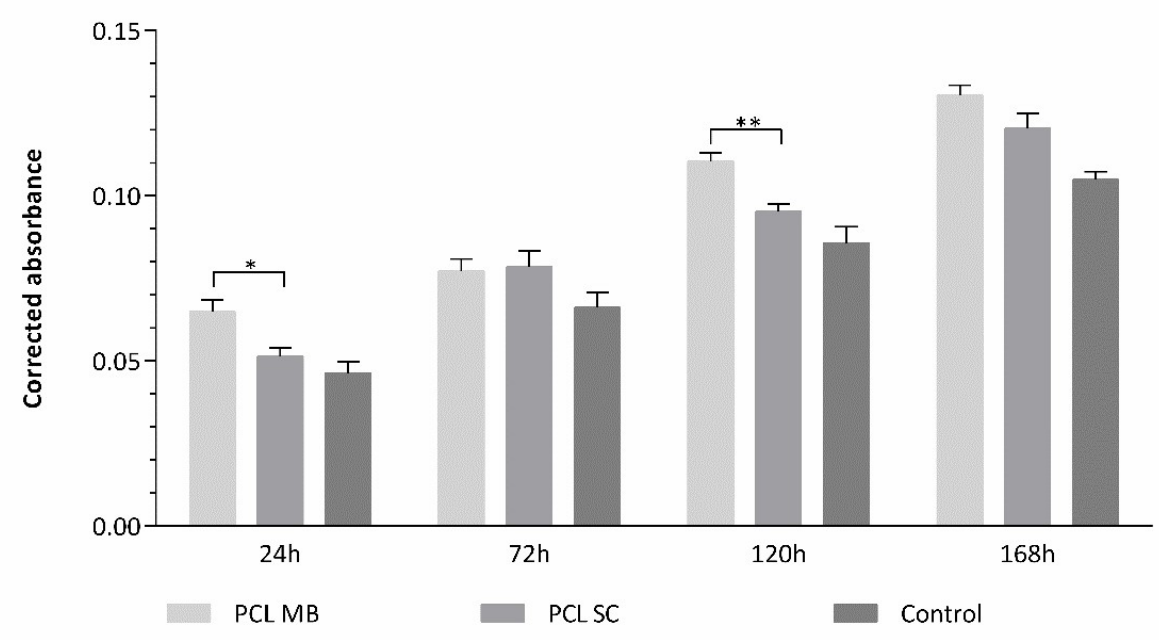

Figure 7. Preliminary cytocompatibility assessment of the PCL groups by Presto Blue ${ }^{\mathrm{TM}}$ viability assay for hDPSCs. Results presented in Mean \pm SE. Differences were considered statistically significant at $\mathrm{P} \leq 0.05$. Results significance are presented through the symbol $\left({ }^{*}\right)$, according to the $\mathrm{P}$ value, with one or two, corresponding to $0.01<\mathrm{P} \leq 0.05$ and $0.001<\mathrm{P} 0.01 ; 0.0001<\mathrm{P} \leq 0.001$ and $\mathrm{P}$ $\leq 0.0001$, respectively.

Table 3. Preliminary cytocompatibility assessment of the PCL groups by Presto Blue ${ }^{\mathrm{TM}}$ viability assay for hDPSCs. Corrected absorbance results are presented in Mean $\pm \mathrm{SE}$.

\begin{tabular}{ccccccc}
\hline & \multicolumn{2}{c}{ PCL MB } & \multicolumn{2}{c}{ PCL SC } & \multicolumn{2}{c}{ hDPSCs Control } \\
& Mean & SE & Mean & SE & Mean & SE \\
\hline $24 \mathrm{~h}$ & 0.065 & 0.004 & 0.051 & 0.003 & 0.046 & 0.004 \\
$72 \mathrm{~h}$ & 0.077 & 0.004 & 0.078 & 0.005 & 0.066 & 0.005 \\
$120 \mathrm{~h}$ & 0.111 & 0.002 & 0.095 & 0.003 & 0.086 & 0.005 \\
$168 \mathrm{~h}$ & 0.131 & 0.003 & 0.121 & 0.005 & 0.105 & 0.003 \\
\hline
\end{tabular}

A Presto Blue ${ }^{\mathrm{TM}}$ viability assay was conducted with hDPSCs on the PCL MB (control) and different PCL/HA scaffolds. A control of the cellular populations' health and normal behaviour in culture was considered, as described above. Figure 8 and Tables $4-5$ present the results obtained, for the corrected absorbance and the $\%$ of viability inhibition, when normalized to the values to the control group (PCL MB). Results suggest the incorporation of HA to positively influence hDPSCs viability, with the increase in HA content presenting superior outcomes. As for the best blending techniques, differences between the respective $\mathrm{SC}$ and $\mathrm{MB}$ groups are not statistically significant in this assay, with both $\mathrm{MB}$ and SC groups presenting positive hDPSCs viability outcomes. 

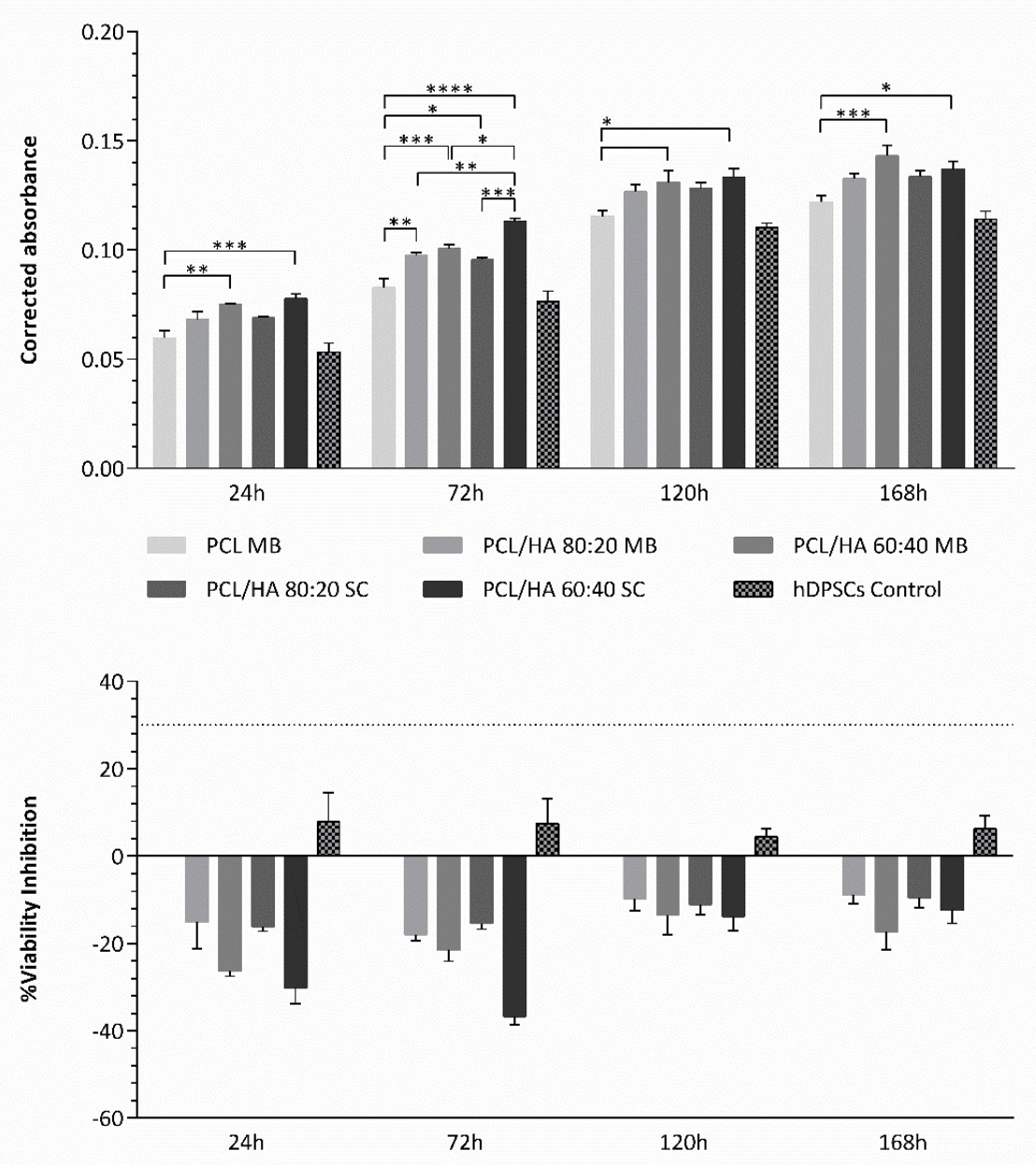

Figure 8. Cytocompatibility assessed by Presto Blue ${ }^{\mathrm{TM}}$ viability assay for hDPSCs. Results presented in Mean \pm SE. Differences were considered statistically significant at $P \leq 0.05$. Results significance are presented through the symbol $(*)$, according to the $\mathrm{P}$ value, with one, two, three or four symbols, corresponding to $0.01<\mathrm{P} \leq 0.05 ; 0.001<\mathrm{P} 0.01 ; 0.0001<\mathrm{P} \leq 0.001$ and $\mathrm{P} \leq 0.0001$, respectively.

Table 4. Cytocompatibility assessed by Presto Blue ${ }^{\mathrm{TM}}$ viability assay for hDPSCs. Corrected absorbance results are presented in Mean \pm SE.

\begin{tabular}{ccccccccccccccc}
\hline & \multicolumn{1}{c}{ PCL MB } & \multicolumn{1}{c}{ MB } & \multicolumn{4}{c}{ SC } & \multicolumn{3}{c}{ hDPSCs } \\
& Mean & SE & Mean & SE & PCL/HA 60:40 & \multicolumn{1}{c}{ PCL/HA 80:20 } & PCL/HA 60:40 & \multicolumn{2}{c}{ Control } \\
& Mean & SE & Mean & SE & Mean & SE & Mean & SE \\
\hline 24h & 0.060 & 0.004 & 0.068 & 0.004 & 0.075 & 0.001 & 0.069 & 0.001 & 0.077 & 0.002 & 0.055 & 0.004 \\
$72 \mathrm{~h}$ & 0.083 & 0.004 & 0.098 & 0.001 & 0.101 & 0.002 & 0.095 & 0.001 & 0.113 & 0.002 & 0.076 & 0.005 \\
$120 \mathrm{~h}$ & 0.115 & 0.003 & 0.127 & 0.003 & 0.131 & 0.005 & 0.128 & 0.003 & 0.131 & 0.004 & 0.110 & 0.002 \\
$168 \mathrm{~h}$ & 0.122 & 0.003 & 0.133 & 0.003 & 0.143 & 0.005 & 0.134 & 0.003 & 0.137 & 0.004 & 0.114 & 0.004 \\
\hline
\end{tabular}

Table 5. Cytocompatibility assessed by Presto Blue ${ }^{\mathrm{TM}}$ viability assay for hDPSCs. Results of \% viability inhibition are presented in Mean \pm SE, normalized to the PCL MB as $0 \%$. 


\begin{tabular}{cccccccccccc}
\hline & \multicolumn{4}{c}{ MB } & \multicolumn{4}{c}{ SC } & \multicolumn{3}{c}{ hDPSCs } \\
& PCL/HA 80:20 & PCL/HA 60:40 & \multicolumn{2}{c}{ PCL/HA 80:20 } & \multicolumn{2}{c}{ PCL/HA 60:40 } & \multicolumn{2}{c}{ Control } \\
& Mean & SE & Mean & SE & Mean & SE & Mean & SE & Mean & SE \\
\hline 24h & -15.15 & 6.09 & -26.39 & 1.14 & -16.20 & 1.04 & -30.25 & 3.56 & 7.81 & 6.64 \\
$72 \mathrm{~h}$ & -18.00 & 1.38 & -21.57 & 2.51 & -15.43 & 1.35 & -36.71 & 1.96 & 7.46 & 5.64 \\
$120 \mathrm{~h}$ & -9.83 & 2.73 & -13.55 & 4.47 & -11.13 & 2.29 & -13.88 & 3.28 & 4.45 & 1.76 \\
$168 \mathrm{~h}$ & -8.87 & 2.05 & -17.32 & 4.09 & -9.63 & 2.15 & -12.39 & 3.02 & 6.26 & 2.95 \\
\hline
\end{tabular}

\subsubsection{Osteogenic differentiation assay}

The osteogenic potential of the scaffolds was assessed by Alizarin Red S (ARS) protocol, following 21 days incubation period, by the detection of mineral deposition, as described in previous works [21,22]. ARS was extracted and further quantified at $405 \mathrm{~nm}$. Results are presented in Figure 9 and Tables 6-7, suggesting that HA incorporation promotes osteogenic differentiation of hDPSCs. This promotion is enhanced in the groups with higher HA content. Differences between the respective blending techniques groups (MB and SC) are not statistically significant, similarly to the cell viability assay.
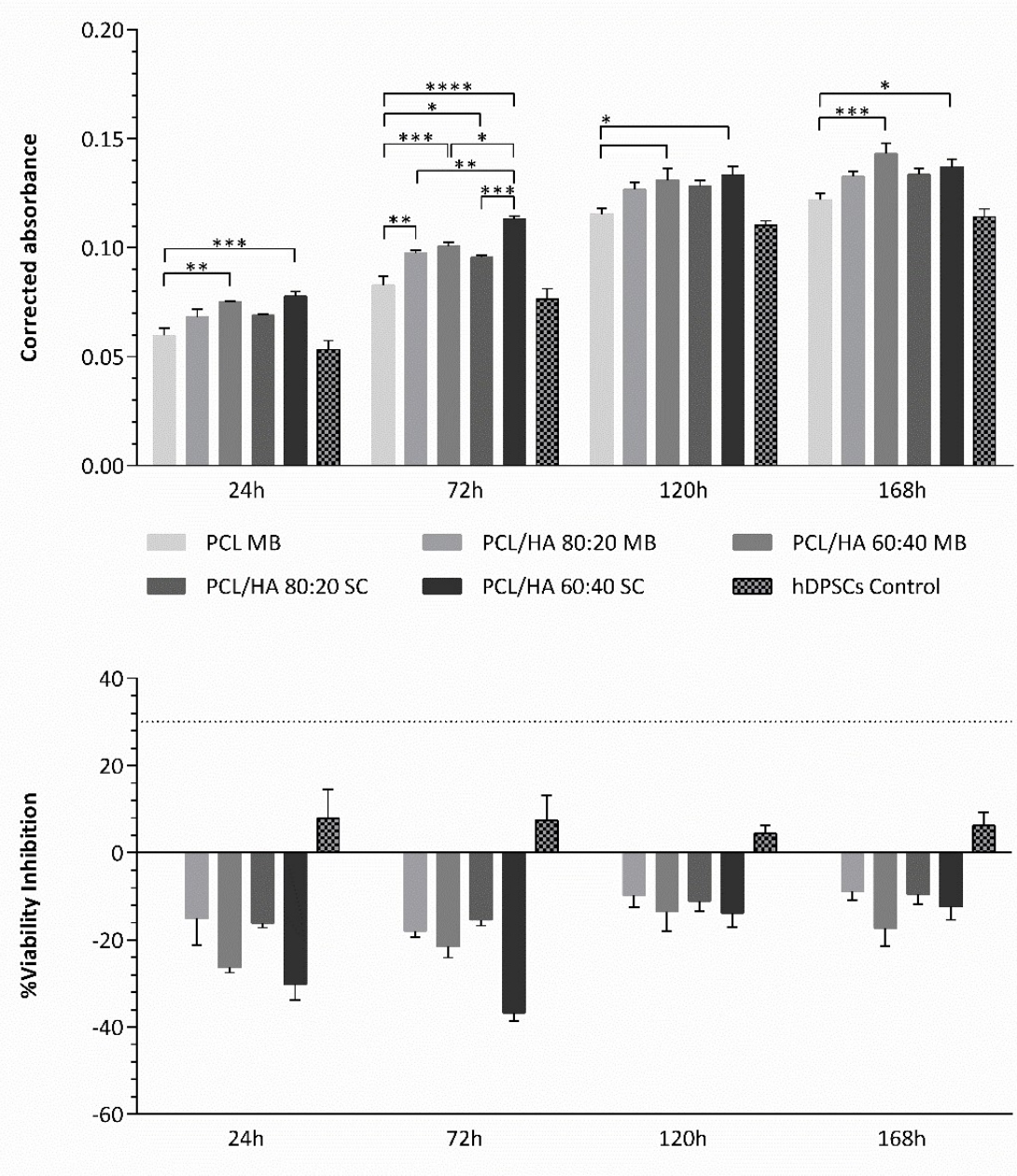

Figure 9. Cytocompatibility assessed by Presto Blue ${ }^{\mathrm{TM}}$ viability assay for hDPSCs. Results presented in Mean \pm SE. Differences were considered statistically significant at $\mathrm{P} \leq 0.05$. Results significance are presented through the symbol $(*)$, according to the $\mathrm{P}$ value, with one, two, three or four symbols, corresponding to $0.01<\mathrm{P} \leq 0.05 ; 0.001<\mathrm{P} 0.01 ; 0.0001<\mathrm{P} \leq 0.001$ and $\mathrm{P} \leq 0.0001$, respectively. 
Table 6. ARS Semi-Quantification in mM between groups. Results presented in Mean \pm SE. "Undif." Stands for "Undiferentiated" and "Dif." Stands for "Differentiated".

\begin{tabular}{cccccccccccccc}
\hline & \multicolumn{1}{c}{ PCL MB } & \multicolumn{4}{c}{ MB } & \multicolumn{4}{c}{ SC } & \multicolumn{2}{c}{ hDPSCs } \\
& & & \multicolumn{1}{c}{ PCL/HA 80:20 } & PCL/HA 60:40 & PCL/HA 80:20 & PCL/HA 60:40 & \multicolumn{2}{c}{ Control } \\
& Mean & SE & Mean & SE & Mean & SE & Mean & SE & Mean & SE & Mean & SE \\
\hline Undif. & 0.184 & 0.004 & 0.422 & 0.043 & 0.494 & 0.015 & 0.332 & 0.031 & 0.500 & 0.024 & 0.053 & 0.004 \\
Dif. & 0.803 & 0.046 & 1.311 & 0.098 & 1.442 & 0.073 & 1.145 & 0.051 & 1.324 & 0.069 & 0.477 & 0.025 \\
\hline
\end{tabular}

Table 7. ARS Semi-Quantification in $\mathrm{mM}$ between groups. Results of \% mineral deposition enhancement are presented in Mean \pm SE, normalized to the PCL MB as $0 \%$.

\begin{tabular}{cccccccccccc}
\hline & \multicolumn{4}{c}{ MB } & \multicolumn{4}{c}{ SC } & \multicolumn{2}{c}{ hDPSCs } \\
& PCL/HA 80:20 & PCL/HA 60:40 & \multicolumn{2}{c}{ PCL/HA 80:20 } & PCL/HA 60:40 & \multicolumn{2}{c}{ Control } \\
& Mean & SE & Mean & SE & Mean & SE & Mean & SE & Mean & SE \\
\hline Undif. & 129.7 & 23.03 & 168.9 & 8.41 & 80.88 & 16.99 & 172.6 & 13.25 & -70.98 & 2.307 \\
Dif. & 63.33 & 12.25 & 79.66 & 9.126 & 42.64 & 6.352 & 65.04 & 8.652 & -40.60 & 3.084 \\
\hline
\end{tabular}

\subsection{Scanning Electronic Microscopy (SEM)}

A SEM analysis was conducted, following in vitro viability assessment. Unseeded devices were also analysed. Images are presented with different magnification on Figure 10 and 11. SEM analysis confirms hDPSCs attachment and proliferation on the scaffolds, presenting normal structure and morphology. Differences between groups could not be assessed, and qualitatively all presented positive outcomes, regarding 3D cell attachment, normal adhesion and morphological structure. 


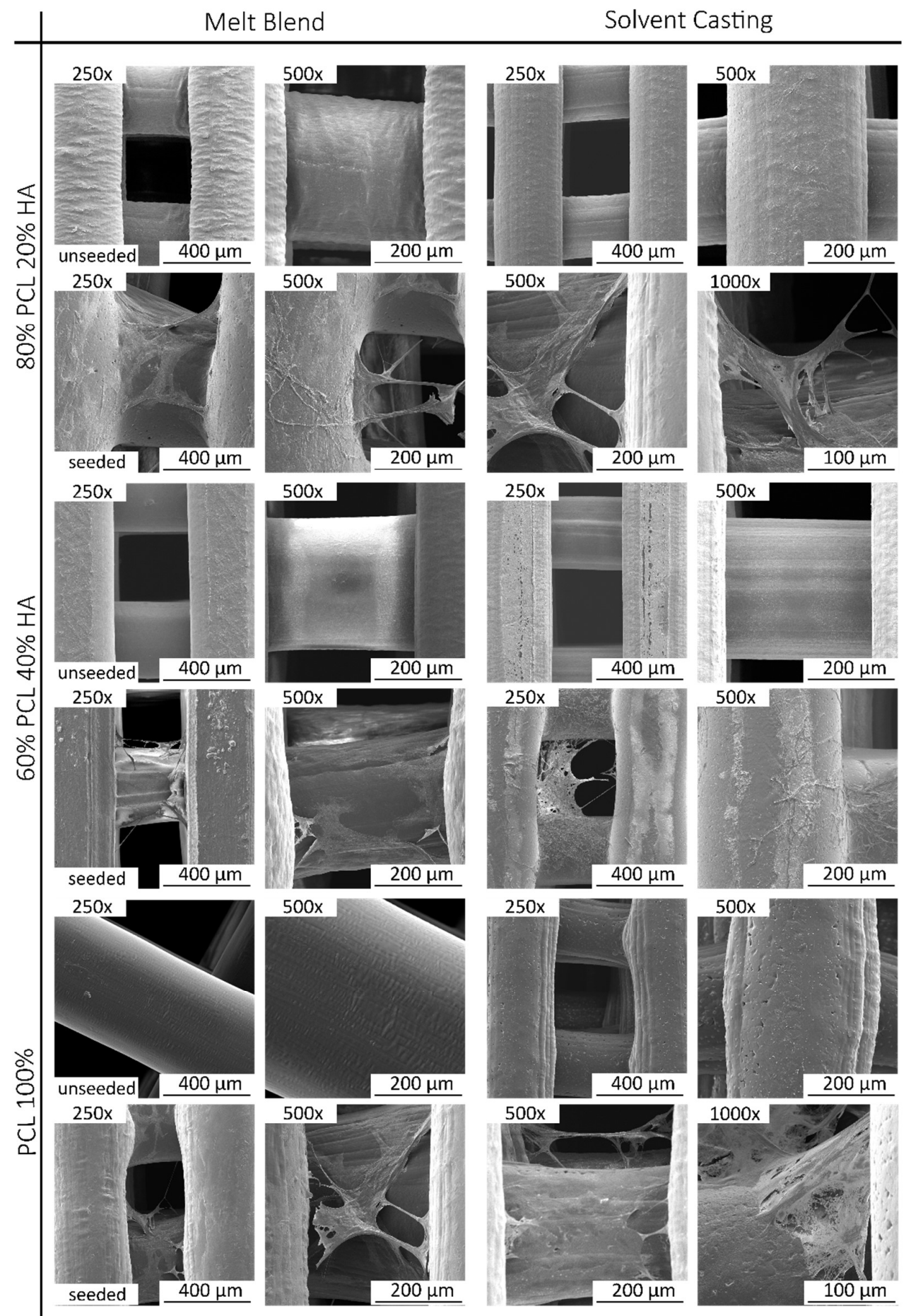

Figure 10. SEM analyses of the seeded and unseeded devices with different magnifications. Images obtained by a high resolution (Schottky) Environmental Scanning Electron Microscope with x-ray microanalysis and Electron Backscattered Diffraction analysis: Quanta 400 FEG ESEM / EDAX Genesis X4M in high vacuum mode. 


\section{hDPSCs}

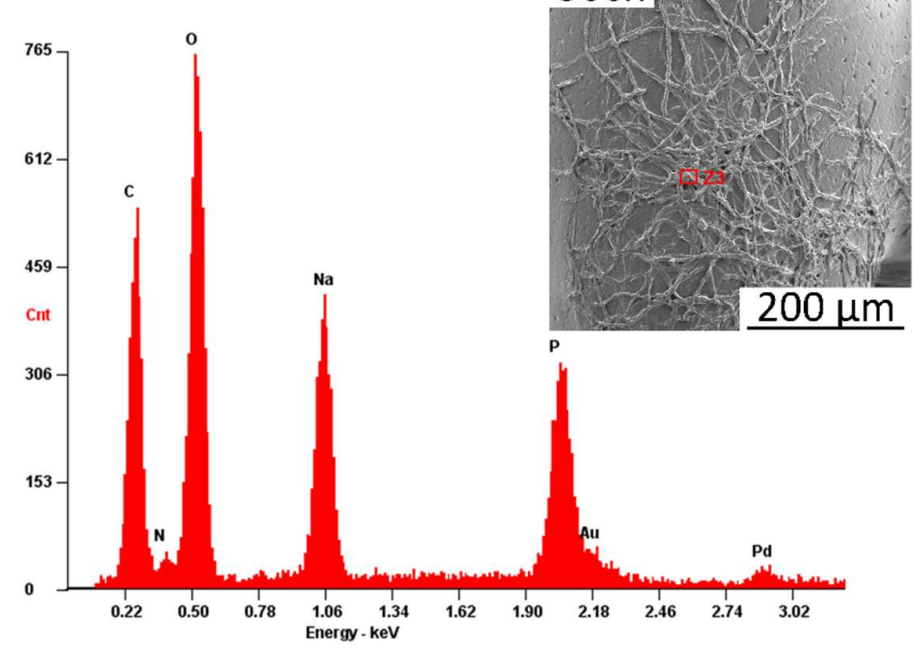

Figure 11. EDX analyses of the seeded devices, by a high resolution (Schottky) Environmental Scanning Electron Microscope with x-ray microanalysis and Electron Backscattered Diffraction analysis: Quanta 400 FEG ESEM / EDAX Genesis X4M in high vacuum mode.

\section{Discussion}

3D porous biodegradable scaffolds have been explored using various techniques in the interest of be suitable as bone substitutes for bone repair and reconstruction. The conventional techniques include $\mathrm{MB}$ and $\mathrm{SC}$, while the new fabrication methods consist of 3D printing technologies, such as extrusion. The optimization of production processes for the dispersion of nanomaterials in polymer matrices and the design of $3 \mathrm{D}$ printing scaffolds, as well the combination of these features, play a critical role in tissue engineering. They contribute to achieve the requirements of 3D scaffolds, and the appropriate physical inter-connections, for an efficient cell permeation and colonization. The current work is focused on the processing of PCL and PCL/HA composites prepared by $\mathrm{MB}$ and $\mathrm{SC}$ methods, using an extrusion-based technique for the development of 3D substitutes for bone tissue engineering. PCL was selected as the major component of scaffolds because it is easy to process by 3D printing, is biodegradable and biocompatible, and possess adequate mechanical strength. However, the hydrophobic surface and lack of osteoconductivity of the PCL matrix represents some disadvantages, which can impair cells adhesion and proliferation [23, 24]. Therefore, HA incorporation was considered, to enhance scaffolds' performance, providing more strength and improving cellular activities, including cell attachment, proliferation, and differentiation [9]. Moreover, in human body nearly $70 \%$ of hard tissues are composed of HA and are clinically used for orthopaedic and dental repairs [25]. Considering that usually the amount of ceramic remains under $40 \%$ of the final material weight, and the most used polymer/ceramic weight ratio is $80 / 20$, the weight ratio of polymer/ceramic was defined at $80 / 20$ and $60 / 40$ $w t \%[6]$. These proportions allow to evaluate and correlate this work outcomes with other previous works and also to prevent 3D printing difficulties, such as nozzle clogging and nonuniform deposition of the composite material filaments. Regarding the mixture techniques to produce PCL and PCL/HA composites, MB and SC methods are widely used for this purpose, as they allow easy way production of composites and provide good dispersion of fillers into polymers matrix. While the MB method depends on high temperatures to mixture the two materials, the SC implies the use of an organic solvent to promote polymer dissolution and improve HA nanoparticles dispersion. Macroporosity of the scaffolds was designed using an extrusion-based 3D printing technique to obtain 
well-defined and interconnected pores for efficient cell colonization and infiltration, and consequently cell adhesion and ingrowth.

Chemical composition of the composites was analysed by FTIR to investigate the functional groups of the PCL/HA composite scaffolds and any chemical interactions among the components of PCL and HA. The spectra of PCL/HA composite scaffolds presented all characteristic bands of PCL and HA, and only differed in terms of intensity, confirming the lack of chemical interaction. These results are consistent with those reported by others works [26, 27]. Chemical analysis indicate that MB and SC composites have been properly prepared and successfully $3 \mathrm{D}$ printed with integration of the characteristic peaks of the individual components.

Regarding EDX mapping data, the HA was detected as distributed throughout the filaments of composites produced from both preparation methods. Comparing the EDX spectra of scaffolds obtained by the different mixture techniques, it is evident that in the MB method, bioceramic particles are less embedded on PCL matrix and consequently more elements of the HA are detected on these samples' surface.

Thermal analysis revealed that the thermal behavior of the scaffolds is influenced by the solvent addition and the dispersion characteristics of the ceramic in polymer. The degrees of crystallinity in SC samples are similar with an evident increase in MB composites.he addition of HA promotes a decreased in the endothermic melting enthalpies. Koupaei and Karkhaneh [28] and Pedrosa et al [29] reported the same behaviour in PCL/HA scaffolds and in PCL/HA membranes, respectively. These results can be explained due to the high crystallinity of HA that may alter the crystalline properties of the polymer and accelerate nucleation of the PCL chain segments. Furthermore, extrusion-based 3D printing technique also induces oriented crystallisation due to the formation of row nuclei, enhanced by the flow stress applied to the molten polymer [30,31]. Polymer crystallinity determines the mechanical properties of the produced devices and is a crucial point when considering bone tissue engineering applications [28, 30]. TGA thermograms reveal thermal stability in all samples at the processing temperatures used for composites preparation and scaffolds fabrication. Therefore, SC and MB are confirmed as viable methods for mixtures preparation and the extrusion-based technique maintains the integrity of the composites.

The fabricated scaffolds present homogeneous 3D structure and similar porosity. Micro-CT does not allow a precise analysis of HA particles as the spatial resolution limit is between $6-30 \mu \mathrm{m}$. Nevertheless, with this analysis it was possible to verify that in both mixture methods no aggregates above this size are formed. For this reason, and to compare the morphological characteristics of the fabricated scaffolds, in particular filament and pore size, additionally studies of the scaffolds' surface were conducted by SEM. As for the qualitative analysis of the images, SEM analysis revealed a homogeneous distribution of the HA on the polymer matrix, with some particles exposed on the filament surface and some particles agglomerations, promoting a rougher surface. Cestari et al demonstrate that ceramic filler creates a certain roughness on the surface of the material, which could improve cell adhesion [32]. The solvent addition in the SC method promotes the microporosity and this surface morphology is also corroborated in other works [3335]. DMF is a high boiling point solvent that evaporates slowly. The micropores in the filament surface can be related with these chemical properties, as well as the high polarity. However, as other authors reported, the cause for this distinct architecture is not evident $[34,36]$. As for the semi-quantitative analysis of the SEM images, the 3D printed structures present interconnected pores and uniform pore sizes. The filament and pore size were measured to analyse the structural characteristics of the proposed scaffolds and results are consistent with those of the design parameters with pore size $\sim 310 \mu \mathrm{m}$. Scaffolds 3D structure and pore size has a great effect on cell attachment and proliferation, and it has been reported that pore size above $300 \mu \mathrm{m}$ improved vascularisation and bone ingrowth [34, 37-39].

Regarding results presented in Figure 6, the incorporation of HA in the PCL polymer matrix contributes to the increase of the mechanical properties. However, they do not 
increase proportionally to the increase in the ceramic proportion of the composite. In fact, differences between PCL/HA 80:20 and 60:40 are not statistically significant. The lack of difference between the HA incorporated groups can be explained due to a stabilization on the compressive modulus as of a certain concentration value of HA. Furthermore, the MB method presented for all groups better outcomes regarding mechanical properties, when compared to the SC groups. Finally, the MB method combined with the addition of HA provides the best mechanical response of the scaffolds (compressive modulus and maximum stress). Furthermore, according to the Micro-CT and SEM results, the differences in the mechanical properties are not caused by the porosity, since it is very similar for all the produced scaffolds. However, the micropores observed in the surface of the SC scaffolds may justify the decrease in the compressive strength of the scaffolds. The addition of a fraction of nucleating agents, in this case HA, has a positive influence on crystallinity and mechanical properties. Aliotta et al investigated this correlation using various nucleating agents and a semicrystalline polymer [33]. The evaluated 3D structures present compressive strength and modulus within the same range of human cancellous bone, between 2-12 MPa and 0,01-2 GPa, respectively [7, 35, 36]. Therefore, the PCL/HA scaffolds present adequate mechanical support to be applied as bone tissue substitutes. Additionally, the mechanical properties of the scaffolds can be adjusted as a function of mixture method and HA content, depending on the characteristics of the bone defect. These analyses indicate the MB method as a promising choice for producing scaffolds envisioning bone tissue engineering, combined with the incorporation of HA.

Regarding the cytocompatibility assessment, outcomes for cell viability show that this assay can be considered viable, as the cell population presented normal growth and proliferation in culture, considering the hDPSCs control group. The preliminary assay compared the cytocompatibility of PCL MB and PCL SC, both presenting similar results with no statistically significant differences. However, during most of the assay, PCL MB presented slightly better outcomes, in agreement with the previous characterization assays outcomes. Thus, from this point forward, the PCL MB group was employed as a scaffold control group for further in vitro studies where different PCL/HA formulations were evaluated. Furthermore, data were analysed according to manufacturing instructions and results were interpreted following ISO 10993-5:2009 "Biological evaluation of medical devices" - Part 5 - "Test for in vitro cytotoxicity" guidelines, although this assay is not directly described in the guideline, the authors adapted the interpretation from the MTT assay. This latter has comparable performance with the PrestoBlue ${ }^{\mathrm{TM}}$, however, implies endpoint assays, in contrast with the present assay, that allows live-cell evaluations [40]. Thus, the same cell population and the same scaffolds can be analysed throughout the duration of the experiment. According to the guidelines (annex C), a viability inhibition superior to $30 \%$ is considered a cytotoxic effect. None of the observed groups presented a viability inhibition superior to $30 \%$ and therefore, can be considered cytocompatible. Overall, PCL/HA scaffolds outperformed the PCL MB scaffolds in terms of cellular viability with higher HA content presenting increasing viability outcomes. Similar results have been previously reported by other groups [7, 26, 41-46]. Regarding blending techniques, differences between the respective SC and MB groups are not statistically significant, with both MB and SC groups presenting positive hDPSCs viability outcomes. Finally, with this assay, the cytocompatibility of all the scaffolds could be confirmed. As for the osteodifferentiation assay, it demonstrated the effect on the osteogenic extension promoted by the incorporation of HA in the PCL scaffolds. All PCL/HA groups presented superior mineral deposition detection, when compared to the PCL MB group. Furthermore, considering the undifferentiated group, the PCL/HA groups were capable of inducing osteogenesis, thus, suggesting the incorporation of HA to induce spontaneous osteogenesis [47]. The differences between PCL/HA groups are not relevant, being the results very similar between groups. The PCL alone was also capable of inducing, although to a lesser extent, intrinsic osteogenesis, in the undifferentiated group, as other groups have reported before [48, 49]. As for the control group, direct comparison with the scaffolds group should not be considered, as 
this group consisted of a 2D culture condition, in contrast with the 3D culture condition from the scaffolds. It has been widely accepted that $3 \mathrm{D}$ cultures present superior differentiation ability, when comparing with 2D cultures [50,51]. This control group, similarly, to the previous assay, was considered as a control of the cell population health and normal behaviour in culture. hDPSCs were selected for this assay due to their preestablished potential towards the osteogenic line and consequent aptitude towards bone tissue regeneration [18, 19]. A previous work compared the differentiation potential of PCL and PCL/HA scaffolds with hDPCs, human umbilical cord mesenchymal stem cells (MSCs) and human bone marrow derived MSCs, with the hDPSCs presenting superior osteogenic outcomes [41]. Other have been successfully applying hDPSCs for the evaluation of PCL/HA scaffolds for bone tissue regeneration $[46,52,53]$.

\section{Materials and Methods}

\subsection{Composites preparation and Scaffolds production}

Melt blending and solvent casting methods were used for the preparation of composites with PCL (commercially available as CAPA $6500-\mathrm{Mw}=50$ 000, Perstop Caprolactones (Cheshire, UK)) and HA (Sigma Aldrich (USA), with particle size $<200 \mathrm{~nm}$ ). In the MB method, the PCL pellets were heated in a mortar at $100{ }^{\circ} \mathrm{C}$. After $40 \mathrm{~min}$, HA was added to the melted PCL under constant agitation until a homogeneous solution was obtained. The resulting composite was left to dry and following sliced into small spheres $(\approx 1.5 \mathrm{~cm}$ in diameter), for later deposition in the extrusion-based equipment. In the SC the solid components (PCL and HA) were dissolved in N,N Dimethylformamide (DMF, from Merck KGaA ${ }^{\circ}$, Germany). The total amount of DMF was calculated as a function of PCL mass, considering $2 \mathrm{~mL}$ DMF for each $0.5 \mathrm{~g}$ PCL [54]. For a complete dissolution of the PCL into the solutions, an ultrasonic homogenizer (UP200Ht, Hielscher, Ultrasound Technology) was used and the following parameters were applied: 4 cycles with power of $50 \mathrm{~W}$, during $5 \mathrm{~min}$ with a break of $2 \mathrm{~min}$. After complete dissolution of PCL and dispersion of HA in DMF, both solutions were mixed using a magnetic stirrer (500 rpm) for 10 minutes. Following, the solution was placed into petri dishes and left to dry in fume hood until complete solvent evaporation. The obtained samples with $\approx 2 \mathrm{~mm}$ thickness were then sliced into small squares, for further use. Error! Reference source not found. summarizes the composition of the materials prepared under these conditions.

Table 8. Composition of the prepared mixtures.

\begin{tabular}{cccc}
\hline Sample & Mixture method & PCL (wt\%) & HA (wt\%) \\
\hline PCL MB & MB & 100 & - \\
PCL SC & SC & 100 & - \\
PCL/HA 80:20 MB & MB & 80 & 20 \\
PCL/HA 80:20 SC & SC & 80 & 20 \\
PCL/HA 60:40 MB & MB & 60 & 40 \\
PCL/HA 60:40 SC & SC & 60 & 40 \\
\hline
\end{tabular}

Cylindrical scaffolds of PCL and PCL/HA composites were produced using an additive manufacturing system, named as Biomate [55]. Scaffolds were fabricated using a deposition velocity of $300 \mathrm{~mm} / \mathrm{min}$, a screw rotation velocity of $10-20 \mathrm{rpm}$ and a melting temperature of $70-80^{\circ} \mathrm{C}$. The final scaffolds presented $10 \mathrm{~mm}$ diameter, $2.5 \mathrm{~mm}$ height, pore geometry of $0^{\circ} / 90^{\circ}$, pore size of $0.35 \mathrm{~mm}$ and filament diameter of $0.3 \mathrm{~mm}$.

\subsection{Characterizaton of $3 D$ scaffolds}

The chemical composition of the samples was analysed by Alpha FT-IR spectrometer (Bruker, Belgium) and Opus Software. All tests were performed at room temperature, in a spectral range of $400-4000 \mathrm{~cm}^{-1}$, with a resolution of $4 \mathrm{~cm}^{-1}$ in a total of 64 scans. 3D printed scaffolds were thermally characterized by Differential Scanning Calorimetry 
(DSC) and Thermogravimetric Analysis (TGA) techniques, using the STA 6000 equipment (Perkin Elmer). DSC analyses were performed for the evaluation of crystallization and melting temperatures of the scaffolds. The samples were heated from 30 to $100^{\circ} \mathrm{C}$ at a heating rate of $10^{\circ} \mathrm{C} / \mathrm{min}$ and maintained at $100^{\circ} \mathrm{C}$ for 2 minutes. Then, the samples were cooled from $100^{\circ} \mathrm{C}$ to $15^{\circ} \mathrm{C}$ and heated from $15^{\circ} \mathrm{C}$ to $100^{\circ} \mathrm{C}$, at the same rate, to obtain the crystallization $\left(\mathrm{T}_{\mathrm{c}}\right)$ and melting temperatures $\left(\mathrm{T}_{\mathrm{m}}\right)$, respectively. The analysis of the mass loss of the sample as a function of temperature was performed by TGA technique, applying a heating cycle from $15^{\circ} \mathrm{C}$ to $700^{\circ} \mathrm{C}$, at a rate of $10^{\circ} \mathrm{C} / \mathrm{min}$. The degree of crystallinity, $\mathrm{X}_{\mathrm{c}}$, of composites were calculated from the areas of the corresponding DSC melting peaks using the following equation [56]:

$$
\mathrm{X}_{\mathrm{c}}=\frac{\Delta \mathrm{H}_{\mathrm{m}}}{\Delta \mathrm{H}_{0} \times \mathrm{X}_{\mathrm{PCL}}} \times 100
$$

where $\mathrm{XPCL}_{\mathrm{PC}}$ represents the weight fraction of PCL in the composite, $\Delta \mathrm{H}_{0}$ the heat of fusion of $100 \%$ crystalline PCL $(139.5 \mathrm{~J} / \mathrm{g}[57,58])$ and $\Delta \mathrm{H}_{\mathrm{m}}$ the peak area of the melting range considered. All the runs were performed in triplicate with samples of 6-7 $\mathrm{mg}$ placed in alumina pans. Empty pans were used as reference. The flow rate of nitrogen was 20 $\mathrm{mL} / \mathrm{min}$ during all the runs. Micro X-ray computed tomographic analysis was performed using a high resolution 1174 Skyscan system (Skyscan, Belgium). The cylindrically shaped scaffolds were mounted on the stage within the imaging system and scanned at $800 \mu \mathrm{A}$ current, $50 \mathrm{kV}$ voltage, with an exposer time of $6000 \mathrm{~ms}$, rotation step of 0.6 degrees, frame averaging of 2 and without filter. Following the image acquisition, images were reconstructed to 2D cross-sections, beam hardening was corrected, and sufficient smoothing was applied to remove the excess of background noise. NRecon software was used for the reconstruction. All the parameters of the scan and reconstruction settings were identical to the ones used for the samples. To distinguish the solid polymeric material from the void regions, a global thresholding procedure was performed. Porosity was obtained, through CTAn software, and all the calculations were performed within a Volume of Interest (VOI). Each scaffold formulation obtained from MB and SC (PCL, PCL/HA 80:20, PCL/HA 60:40) were scanned 3 times. The porosity was calculated by the average of 3 measurements, from each structure (a total of 9 measurements per group). Morphological images were obtained using CTVox software. The surface morphology of all 3D constructs was analysed by using a scanning electron microscope (SEM) (VEGA 3, TESCAN) that was operated at a voltage of $15 \mathrm{kV}$, after coating the structures with goldpalladium. Image J software v1.43 was used to calculate the mean pore size and filament diameter by measuring at least 5 points. The same samples were also studied by energy dispersive X-ray spectroscopy (EDX) at a voltage of $15 \mathrm{kV}$ to investigate the elemental constituents as well as the atomic percentage of the elements. Compression tests were performed on the PCL and PCL/HA 3D scaffolds to evaluate the effect of the addition of the ceramic on the mechanical properties of the polymer matrix. The cylindrical structures were analysed on INSTRON 4505 equipment in a dry state at a rate of $1 \mathrm{~mm} / \mathrm{min}$. Five specimens were tested for each composition.

\subsection{Cytocompatibility analysis}

\subsubsection{Cell culture and maintenance}

hDPSCs were acquired from AllCells, LLC (Cat. DP0037F, Lot N DPSC090411-01) and maintained in MEM $\alpha$, GlutaMAX ${ }^{\mathrm{TM}}$ Supplement, no nucleosides (Gibco, 32561029), supplemented with 10\% (v/v) fetal bovine serum (FBS) (Gibco, A3160802), 100 IU/ml penicillin, 0,1 mg/ml streptomycin (Gibco, 15140122), 2,05 $\mu \mathrm{m} / \mathrm{ml}$ amphotericin B (Gibco, 15290026) and $10 \mathrm{mM}$ HEPES buffer solution (Gibco, 15630122). Cells were maintained at $37^{\circ} \mathrm{C}, 80 \%$ humidified atmosphere and $5 \% \mathrm{CO}_{2}$ environment. A previous work details the characterization of these cells [18].

4.3.2 Cell viability assay 
For the assessment of the samples' cytocompatibility, a Presto Blue ${ }^{\mathrm{TM}}$ viability assay was performed with hDPSCs, as previously described by Alvites et al [59]. The 3D scaffolds were sterilized by gamma radiation at $25 \mathrm{kGy}$, by a Red Perspex dosimeter. A dynamic seeding protocol was considered for the association of the biomaterial with the cellular system. Briefly, scaffolds were incubated with hDPSCs at a density of $2 \times 10^{5}$ cells per scaffold, for 8 hours, at $37^{\circ} \mathrm{C}, 5 \% \mathrm{CO}_{2}$. Following, scaffolds were placed on a nontreated 24-well plate and concealed with complete media. A final group without scaffolds and with only cells was considered for validation of the cell population health and normal proliferation in culture. Scaffolds were incubated for $24 \mathrm{~h}, 72 \mathrm{~h}, 120 \mathrm{~h}$ and $168 \mathrm{~h}$ and the cells metabolic activity was evaluated by Presto Blue ${ }^{\mathrm{TM}}$ viability assay. This assay is based on a resazurin solution, that it reduced by living and metabolically active cells, resulting in colour changes in the medium that is quantitatively assessed by ultraviolet-visible spectrophotometry. For each group, unseeded wells were considered as blanks. At every time point culture medium was replaced by fresh complete medium to each well, with $10 \%(\mathrm{v} / \mathrm{v})$ of 10x Presto Blue cell viability reagent (Invitrogen, A13262). Following, cells were incubated for 1 hour at $37^{\circ} \mathrm{C}, 5 \% \mathrm{CO}_{2}$. At this point, supernatant was removed from each well and placed on 96 well plate, and further analysed on a Thermo Scientific ${ }^{\mathrm{TM}}$ Multiskan ${ }^{\mathrm{TM}}$ FC Microplate Photometer (Thermo Scientific TM, 51119000)., at 570nm and $595 \mathrm{~nm}$. The Presto Blue assay allows live-cell assay, and as such, well were gently washed with Dulbecco's phosphate-buffered saline solution (DPBS, Gibco, 14190169) until complete removal of the dye and fresh standard culture medium added. For this reagent, the excitation wavelength is $570 \mathrm{~nm}$, and emission is $595 \mathrm{~nm}$. For each well, absorbance at $595 \mathrm{~nm}$ was subtracted from the value obtained at $570 \mathrm{~nm}$. Corrected absorbance values for the seeded wells were further calculated, by the subtraction of the average of the correspondent blank wells. Triplicate measurements were considered for each well ate every time-point. Data were further processed and normalized to the mean of the gold standard group (PCL MB), and presented in \% of viability inhibition, comparing to the gold standard group.

\subsubsection{Osteogenic differentiation assay}

Samples were evaluated as to their capacity to promote or inhibit osteogenic differentiation of the hDPSCs. Similarly, to the viability assay, scaffolds were seeded by a dynamic seeding protocol. After 3 days in culture, standard culture media was removed, and osteogenic differentiation media was added (StemPro ${ }^{\mathrm{TM}}$ Osteogenesis Differentiation Kit, A1007201, Gibco ${ }^{\mathrm{TM}}$ ). Control wells for each biomaterial group were left in standard culture media. Media was changed every 3 days for 21 days. An Alizarin Red S (ARS) staining solution (TMS-008-C, Merk-Millipore) was used for semi-quantitative analysis of the osteogenic differentiation process, as described in previous works [21, 22]. Briefly, cells were fixated in $4 \%$ formaldehyde $(3.7-4 \%$ buffered to $\mathrm{pH}$, 252931.1315, Panreac AppliChem) and stained with 40mM ARS solution. Cells were incubated for 30 minutes under gentle agitation. From this point, wells were carefully washed with DPBS until dye was removed from the supernatant. Considering the non-transparent characteristic of the samples, a qualitative assessment could not be performed at this point. Further semiquantitative analysis was performed by adding a 10\% acetic acid solution (ARK2183, Sigma-Aldrich) to the wells. Collection of the cells and mineral deposition was further accessed by scraping of the wells. Content of each well was individually placed on an $85^{\circ} \mathrm{C}$ water bath for 10 minutes, following immediate immersion on ice for 5 minutes. Samples were further centrifuged, and absorbance values at $405 \mathrm{~nm}$ were taken in a Thermo Scientific ${ }^{\mathrm{TM}}$ Multiskan ${ }^{\mathrm{TM}}$ FC Microplate Photometer.

\subsubsection{Scanning Electronic Microscopy (SEM)}

Scaffolds previously used on the cytocompatibility studies were further removed from the plates and fixated for SEM analysis, based on the Utah State University Biological Sample Fixation protocol. In brief, scaffolds were washed with 0,1M HEPES (Merck®, PHG0001) 3 times and further fixated in a 2\% glutaraldehyde (Merck $®$, G5882) buffered solution overnight. Fixative was then removed, and scaffolds washed with HEPES 3 times, 
5 minutes each, under gentle agitation. From this point, samples were subjected to a crescent series of ethanol (50\%,70\%,95\% and 99\%) for dehydration, 2-3 times for 10 to 15 minutes each. Following, scaffolds were soaked in a crescent series of hexamethyldisilazane (HMDS - Alfa Aesar, A15139)-alcohol solution (1:2; 1:1; 2:1) until complete impregnation in a 98\% HMDS solution, 3 times for 15 minutes. Finally, HMDS was removed from the wells and left to evaporate on an air flow chamber overnight. Samples were coated with Au/Pd by sputtering (SPI Module Sputter Coater) and the SEM / EDX exam was performed using a high resolution (Schottky) Environmental Scanning Electron Microscope with x-ray microanalysis and Electron Backscattered Diffraction analysis: Quanta 400 FEG ESEM / EDAX Genesis X4M in high vacuum mode.

\subsection{Statistical analysis}

Statistical analysis was performed with GraphPad Prism, GraphPad Software, La Jolla California USA. Results are presented as Mean \pm Standard Deviation of the Mean (SE). One-Way ANOVA with Tukey multicomparison test was employed for statistical analysis. Differences were considered statistically significant at $\mathrm{P} \leq 0.05$. Results significance are presented with the symbol $\left({ }^{*}\right)$, according to $\mathrm{P}$ values with one, two, three or four of the symbols $\left(^{*}\right)$ corresponding to $0.01<p \leq 0.05,0.001<p \leq 0.01,0.0001<p \leq$ 0.001 and $\mathrm{p} \leq 0.0001$, respectively.

\section{Conclusions}

In this study, PCL/HA composites were prepared by melt blending and solvent casting methods and processed using an extrusion-based technology to obtain 3D scaffolds with well-defined geometry and pore interconnectivity. The incorporation of HA increased the degree of crystallinity and improved the mechanical properties of the scaffolds. This effect was also observed on the MB produced scaffolds, comparing to SC scaffolds, possibly affected by the incorporation of the organic solvent DMF. Furthermore, HA presence was correlated with improved osteogenic activity. As for the HA incorporation proportion, overall, no statistically significant differences were observed, although, morphologically, the 60:40 presented the best homogeneity requirements. Considering these preliminary observations, the PCL/HA MB scaffolds represent fair candidates for bone tissue engineering studies and further in vitro and in vivo studies are envisioned as to reinforce and support these findings.

Author Contributions: Conceptualization, S.B., M.V.B, N.A. and A.C.M.; methodology, S.B., M.V.B., R.F., S.P., A.R.C., R.D.A., T.P., T.V., A.C.S.; software, M.V.B., S.B., S.P., R.F., T.P., T.V. and A.M.; validation, M.V.B., S.B., S.P., A.R.C., F.G. and R.F.; formal analysis, S.B., M.V.B., S.P., A.R.C., R.D.A., R.F.; investigation, M.V.B., S.B., N.A., A.M., A.C.M.; resources, S.B., M.V.B., A.M., N.A. and A.C.M.; data curation, M.V.B and S.B.; writing-original draft preparation, S.B. and M.V.B.; writing-review and editing, M.V.B. and S.B.; visualization, S.B., M.V.B., S.P., R.D.A., A.C.S., R.F., T.P., T.V., A.R.C., A.M., N.A., F.G., and A.C.M.; supervision, A.M., N.A. and A.C.M.; project administration, N.A. and A.C.M.; funding acquisition, N.A. and A.C.M. All authors have read and agreed to the published version of the manuscript.

Funding: This work was developed within the scope of the project insitu.Biomas - Reinvent biomanufacturing systems by using an usability approach for insitu clinic temporary implants fabrication, with the reference POCI-01-0247-FEDER-017771 from the Portuguese National Innovation Agency, and supported by the Fundação para a Ciência e a Tecnologia (FCT) and Centro2020 through the following Projects: UIDB/04044/2020, UIDP/04044/2020, PEstOE/AGR/UI0211/2011 and PAMI - ROTEIRO/0328/2013 (№ 022158). Mariana Vieira Branquinho (SFRH/BD/146172/2019), Ana Catarina Sousa (SFRH/BD/146689/2019) and Rui Damásio Alvites (SFRH/BD/116118/2016), acknowledge FCT, for financial support.

Institutional Review Board Statement: Not applicable.

Informed Consent Statement: Not applicable. 
Data Availability Statement: The data that support the findings of this study are available from the corresponding author on request.

Acknowledgments: The authors acknowledge Daniela Silva from the Scanning Electronic Microscopy Laboratory, Materials Centre of the University of Porto.

Conflicts of Interest: The authors declare no conflict of interest regarding the publication of this article.

$\begin{array}{ll}\text { Abbreviations } \\ \text { ARS } & \text { Alizarin Red S } \\ \text { CF } & \text { Chloroform } \\ \text { DCM } & \text { Dichloromethane } \\ \text { DMF } & \text { Dimethylformamide } \\ \text { DSC } & \text { Differential Scanning Calorimetry } \\ \text { EDX } & \text { Energy dispersive X-ray spectroscopy } \\ \text { FBS } & \text { Fetal bovine serum } \\ \text { FTIR } & \text { Fourier Transform Infrared analysis } \\ \text { HA } & \text { Hydroxyapatite } \\ \text { hDPSCs } & \text { Human Dental Pulp stem/stromal cells } \\ \text { HFIP } & \text { 1,1,1,3,3,3-hexafluoro-2-propanol } \\ \text { HMDS } & \text { Hexamethyldisilazane } \\ \text { MB } & \text { Melt blending } \\ \text { MC } & \text { Methylene chloride } \\ \text { MSCs } & \text { Mesenchymal stem cells } \\ \text { PCL } & \text { Polycaprolactone } \\ \text { PLA } & \text { Polylactic acid } \\ \text { PLGA } & \text { Poly(lactic-co-glycolic) acid } \\ \text { SC } & \text { Solvent casting } \\ \text { SE } & \text { Standard deviation of the mean } \\ \text { SEM } & \text { Scanning electron microscopy } \\ \text { Tc } & \text { Crystallization Temperature } \\ \text { TGA } & \text { Thermogravimetric Analysis } \\ \text { Tm } & \text { Melting temperature } \\ & \end{array}$

\section{References}

1. Nair LS, Laurencin CT. Polymers as Biomaterials for Tissue Engineering and Controlled Drug Delivery. Tissue Engineering I2006. p. 47-90.

2. Rasoulianboroujeni M, Fahimipour F, Shah P, Khoshroo K, Tahriri M, Eslami H. Materials Science \& Engineering C Development of 3D-printed PLGA / TiO 2 nanocomposite sca ff olds for bone tissue engineering applications. 2019;96(September 2018):105-13.

3. Sundelacruz S, Kaplan DL. Stem cell- and scaffold-based tissue engineering approaches to osteochondral regenerative medicine. Seminars in Cell and Developmental Biology. 2009;20(6):646-55.

4. $\quad$ O'Brien FJ. Biomaterials \& scaffolds for tissue engineering. Materials Today. 2011;14(3):88-95. 
5. Pattanashetti NA, Biscaia S, Moura C, Mitchell GR, Kariduraganavar MY. Development of novel 3D scaffolds using BioExtruder by the incorporation of silica into polycaprolactone matrix for bone tissue engineering. Materials Today Communications. 2019;21(May):100651.

6. Babilotte J, Guduric V, Le Nihouannen D, Naveau A, Fricain JC, Catros S. 3D printed polymer-mineral composite biomaterials for bone tissue engineering: Fabrication and characterization. Journal of Biomedical Materials Research - Part B Applied Biomaterials. 2019;107(8):2579-95.

7. Gómez-Lizárraga KK, Flores-Morales C, Del Prado-Audelo ML, Álvarez-Pérez MA, Piña-Barba MC, Escobedo C. Polycaprolactone- and polycaprolactone/ceramic-based 3D-bioplotted porous scaffolds for bone regeneration: A comparative study. Materials Science and Engineering C. 2017;79(2017):326-35.

8. Acutis A, Maria C, Vozzi G. Multimaterial and Multiscale Rapid Prototyping of Patient-Specific Scaffold. Advances in Science and Technology. 2016;100:151-8.

9. Fathi-achachelouei M, Knopf-marques H, Evelise C. Use of Nanoparticles in Tissue Engineering and Regenerative Medicine. 2019;7(May):1-22.

10. Lebourg M, Antón JS, Ribelles JLG. Hybrid structure in PCL-HAp scaffold resulting from biomimetic apatite growth. Journal of Materials Science: Materials in Medicine. 2010;21(1):33-44.

11. Madfa AA, Al-sanabani JS, Madfa AA, Al-sanabani FA. Application of Calcium Phosphate Materials in Dentistry Application of Calcium Phosphate Materials in Dentistry. 2014;2013(February):1-12.

12. Kumar K, Deepalekshmi S, Mariappan P, Basheer R, Mariam AA-m. Polymer Nanocomposites in Biomedical Engineering2019 2019.

13. Patlolla A, Collins G, Livingston Arinzeh T. Solvent-dependent properties of electrospun fibrous composites for bone tissue regeneration. Acta Biomaterialia. 2010;6(1):90-101.

14. Choudhury M, Mohanty S, Nayak S. Effect of Different Solvents in Solvent Casting of Porous caffolds - In Biomedical and Tissue Engineering Applications. Journal of Tissue Science \& Engineering. 2015;06(01):1-7.

15. Guan R, Dai H, Li C, Liu J, Xu J. Effect of casting solvent on the morphology and performance of sulfonated polyethersulfone membranes. Journal of Membrane Science. 2006;277(1-2):148-56.

16. Kim J, Kim B, Jung B, Kang YS, Ha HY, Oh IH, et al. Effect of casting solvent on morphology and physical properties of partially sulfonated polystyrene-block-poly(ethylene-ran-butylene)-block-polystyrene copolymers. Macromolecular Rapid Communications. 2002;23(13):753-6.

17. Robertson GP, Mikhailenko SD, Wang K, Xing P, Guiver MD, Kaliaguine S. Casting solvent interactions with sulfonated poly(ether ether ketone) during proton exchange membrane fabrication. Journal of Membrane Science. 2003;219(1-2):113-21.

18. Campos JM, Sousa AC, Caseiro AR, Pedrosa SS, Pinto PO, Branquinho VM, et al. Dental pulp stem cells and Bonelike ${ }^{\circledR}$ for bone regeneration in ovine model. Regenerative Biomaterials. 2019;6(1):49-59.

19. Caseiro AR, Alvites R, Pedrosa SS, Campos JM, Reis IL, Santos JD, et al. The potential clinical application of mesenchymal stem cells from the dental pulp (DPSCs) for bone regeneration. Frontiers in Stem Cell and Regenerative Medicine Research2017. p. 21-70.

20. Caseiro AR, Pedrosa SS, Ivanova G, Branquinho MV, Almeida A, Faria F, et al. Mesenchymal Stem/Stromal Cells metabolomic and bioactive factors profiles: A comparative analysis on the umbilical cord and dental pulp derived Stem/ Stromal Cells secretome. PLoS ONE. 2019;14(11):1-33.

21. Alvites RD, Branquinho VM, Caseiro AR, Amorim I, Santos Pedrosa S, Rêma A, et al. Rat Olfactory Mucosa Mesenchymal Stem/Stromal Cells (OM-MSCs): A Characterization Study. International Journal of Cell Biology. 2020;2020.

22. Caseiro AR, Ivanova G, Pedrosa SS, Branquinho VM, Georgieva P, Barbosa PP, et al. Human umbilical cord blood plasma as an alternative to animal sera for mesenchymal stromal cells in vitro expansion - A multicomponent metabolomic analysis. PLoS ONE. 2018;13(10):1-35. 
23. Ma J, Lin L, Zuo Y, Zou Q, Ren X, Li J, et al. Modification of 3D printed PCL scaffolds by PVAc and HA to enhance cytocompatibility and osteogenesis. RSC advances. 2019;9(10):5338-46.

24. Montanheiro TLdA, Ribas RG, Montagna LS, Menezes BRCd, Schatkoski VM, Rodrigues KF, et al. A brief review concerning the latest advances in the influence of nanoparticle reinforcement into polymeric-matrix biomaterials. Journal of Biomaterials Science, Polymer Edition. 2020;31(14):1869-93.

25. Hassan M, Dave K, Chandrawati R, Dehghani F, Gomes VG. 3D printing of biopolymer nanocomposites for tissue engineering: Nanomaterials, processing and structure-function relation. European Polymer Journal. 2019;121:109340.

26. El-Habashy SE, Eltaher HM, Gaballah A, Zaki EI, Mehanna RA, El-Kamel AH. Hybrid bioactive hydroxyapatite/polycaprolactone nanoparticles for enhanced osteogenesis. Materials Science and Engineering C. 2021;119:111599.

27. Gautam S, Sharma C, Purohit SD, Singh H, Dinda AK, Potdar PD, et al. Gelatin-polycaprolactone-nanohydroxyapatite electrospun nanocomposite scaffold for bone tissue engineering. Materials Science and Engineering C. 2021;119(September 2020):111588.

28. Koupaei N, Karkhaneh A. Porous crosslinked polycaprolactone hydroxyapatite networks for bone tissue engineering. Tissue Engineering and Regenerative Medicine. 2016;13(3):251-60.

29. Pedrosa MCG, dos Anjos SA, Mavropoulos E, Bernardo PL, Granjeiro JM, Rossi AM, et al. Structure and biological compatibility of polycaprolactone/zinc-hydroxyapatite electrospun nanofibers for tissue regeneration. Journal of Bioactive and Compatible Polymers. 2021;36(4):314-33.

30. Dubinenko G, Zinoviev A, Bolbasov E, Kozelskaya A, Shesterikov E, Novikov V, et al. Highly filled poly(l-lactic acid)/hydroxyapatite composite for 3D printing of personalized bone tissue engineering scaffolds. Journal of Applied Polymer Science. 2021;138(2).

31. Tojeira A, Biscaia SS, Viana TQ, Sousa IS, Mitchell GR. Controlling Morphology in 3D Printing. Controlling the Morphology of Polymers2016.

32. Cestari F, Petretta M, Yang Y, Motta A, Grigolo B, Sglavo VM. 3D printing of PCL/nano-hydroxyapatite scaffolds derived from biogenic sources for bone tissue engineering. Sustainable Materials and Technologies. 2021;29(May):e00318.

33. Aliotta L, Cinelli P, Coltelli MB, Righetti MC, Gazzano M, Lazzeri A. Effect of nucleating agents on crystallinity and properties of poly (lactic acid) (PLA). European Polymer Journal. 2017;93(May):822-32.

34. Luongo F, Mangano FG, Macchi A, Luongo G, Mangano C. Custom-made synthetic scaffolds for bone reconstruction: a retrospective, multicenter clinical study on 15 patients. BioMed research international. 2016;2016.

35. Nicoll SB. Materials for Bone Graft Substitutes and Osseous Tissue Regeneration. In: Burdick JA, Mauck RL, Burdick JA, Mauck RL, editors. Biomaterials for Tissue Engineering Applications2011. p. 1-564.

36. Osorio-Hernández JO, Suarez MA, Goodall R, Lara-Rodriguez GA, Alfonso I, Figueroa IA. Manufacturing of open-cell Mg foams by replication process and mechanical properties. Materials and Design. 2014;64:136-41.

37. Cho YS, Gwak SJ, Cho YS. Fabrication of polycaprolactone/nano hydroxyapatite (Pcl/nha) 3d scaffold with enhanced in vitro cell response via design for additive manufacturing (dfam). Polymers. 2021;13(9).

38. Murphy CM, Haugh MG, O'Brien FJ. The effect of mean pore size on cell attachment, proliferation and migration in collagenglycosaminoglycan scaffolds for bone tissue engineering. Biomaterials. 2010;31(3):461-6.

39. Radhakrishnan S, Nagarajan S, Belaid H, Farha C, Iatsunskyi I, Coy E, et al. Fabrication of 3D printed antimicrobial polycaprolactone scaffolds for tissue engineering applications. Materials Science and Engineering C. 2021;118(May 2020):111525.

40. Emter R, Natsch A. A fast Resazurin-based live viability assay is equivalent to the MTT-test in the KeratinoSens assay. Toxicology in Vitro. 2015;29(4):688-93.

41. Chuenjitkuntaworn B, Inrung W, Damrongsri D, Mekaapiruk K, Supaphol P, Pavasant P. Polycaprolactone/hydroxyapatite composite scaffolds: Preparation, characterization, and in vitro and in vivo biological responses of human primary bone cells. Journal of Biomedical Materials Research - Part A. 2010;94(1):241-51. 
42. Chuenjitkuntaworn B, Osathanon T, Nowwarote N, Supaphol P, Pavasant P. The efficacy of polycaprolactone/hydroxyapatite scaffold in combination with mesenchymal stem cells for bone tissue engineering. Journal of Biomedical Materials Research - Part A. 2016;104(1):264-71.

43. Lebourg M, Suay Antón J, Gomez Ribelles JL. Characterization of calcium phosphate layers grown on polycaprolactone for tissue engineering purposes. Composites Science and Technology. 2010;70(13):1796-804.

44. Pattanashetti NA, Viana T, Alves N, Mitchell GR, Kariduraganavar MY. Development of novel 3D scaffolds using BioExtruder by varying the content of hydroxyapatite and silica in PCL matrix for bone tissue engineering. Journal of Polymer Research. 2020;27(4). 45. Shkarina S, Shkarin R, Weinhardt V, Melnik E, Vacun G, Kluger P, et al. 3D biodegradable scaffolds of polycaprolactone with silicate-containing hydroxyapatite microparticles for bone tissue engineering: High-resolution tomography and in vitro study. Scientific Reports. 2018;8(1):1-13.

46. Yang X, Yang F, Walboomers XF, Bian Z, Fan M, Jansen JA. The performance of dental pulp stem cells on nanofibrous PCL/gelatin/nHA scaffolds. Journal of Biomedical Materials Research - Part A. 2010;93(1):247-57.

47. Koons GL, Diba M, Mikos AG. Materials design for bone-tissue engineering. Nature Reviews Materials. 2020;5(8):584-603.

48. Woodruff MA, Hutmacher DW. The return of a forgotten polymer - Polycaprolactone in the 21st century. Progress in Polymer Science (Oxford). 2010;35(10):1217-56.

49. Xue R, Qian Y, Li L, Yao G, Yang L, Sun Y. Polycaprolactone nanofiber scaffold enhances the osteogenic differentiation potency of various human tissue-derived mesenchymal stem cells. Stem Cell Research and Therapy. 2017;8(1):1-9.

50. Jensen C, Teng Y. Is It Time to Start Transitioning From 2D to 3D Cell Culture? Frontiers in Molecular Biosciences. 2020;7(March):1-15.

51. Persson M, Lehenkari PP, Berglin L, Turunen S, Finnilä MAJ, Risteli J, et al. Osteogenic Differentiation of Human Mesenchymal Stem cells in a 3D Woven Scaffold. Scientific Reports. 2018;8(1):1-12.

52. Aghazadeh M, Samiei M, Hokmabad VR, Alizadeh E, Jabbari N, Seifalian A, et al. The Effect of Melanocyte Stimulating Hormone and Hydroxyapatite on Osteogenesis in Pulp Stem Cells of Human Teeth Transferred into Polyester Scaffolds. Fibers and Polymers. 2018;19(11):2245-53.

53. Park S, Kim JE, Han J, Jeong S, Lim JW, Lee MC, et al. 3D-Printed Poly(E-Caprolactone)/Hydroxyapatite Scaffolds Modified With Alkaline Hydrolysis Enhance Osteogenesis in Vitro. Polymers. 2021;13(2):1-11.

54. Morouço P, Biscaia S, Viana T, Franco M, Malça C, Mateus A, et al. Fabrication of poly( $\epsilon$-caprolactone) scaffolds reinforced with cellulose nanofibers, with and without the addition of hydroxyapatite nanoparticles. BioMed Research International. 2016 ;2016. 55. Viana T, Biscaia S, Dabrowska E, Franco MC, Carreira P, Morouço P, et al. A Novel Biomanufacturing System to Produce Multi-Material Scaffolds for Tissue Engineering: Concept and Preliminary Results. Applied Mechanics and Materials. 2019;890:2839.

56. Wurm A, Lellinger D, Minakov AA, Skipa T, Pötschke P, Nicula R, et al. Crystallization of poly( $(\varepsilon$-caprolactone)/MWCNT composites: A combined SAXS/WAXS, electrical and thermal conductivity study. Polymer. 2014;55(9):2220-32.

57. Sarasini F, Tirillò J, Puglia D, Dominici F, Santulli C, Boimau K, et al. Biodegradable polycaprolactone-based composites reinforced with ramie and borassus fibres. Composite Structures. 2017;167:20-9.

58. Xin H-yM, Jun J. Poly ( e -caprolactone ) ( PCL )/ cellulose nano-crystal ( CNC ) nanocomposites and foams. Cellulose. 2014;21:2727-41.

59. Alvites RD, Branquinho VM, Sousa AC, Amorim I, Magalhães R, João F, et al. Combined Use of Chitosan and Olfactory Mucosa Mesenchymal Stem/Stromal Cells to Promote Peripheral Nerve Regeneration in Vivo. Stem Cells International. 2021;2021. 